\title{
The MCM v3.3.1 degradation scheme for isoprene
}

\author{
M. E. Jenkin ${ }^{1,2}$, J. C. Young ${ }^{3}$, and A. R. Rickard ${ }^{4,5}$ \\ ${ }^{1}$ Atmospheric Chemistry Services, Okehampton, Devon, EX20 4QB, UK \\ ${ }^{2}$ School of Chemistry, University of Bristol, Cantock's Close, Bristol, BS8 1TS, UK \\ ${ }^{3}$ School of Chemistry, University of Leeds, Leeds, LS2 9JT, UK \\ ${ }^{4}$ Wolfson Atmospheric Chemistry Laboratories, Department of Chemistry, University of York, Heslington, \\ York, YO10 5DD, UK \\ ${ }^{5}$ National Centre for Atmospheric Science, University of York, Heslington, York, YO10 5DD, UK
}

Correspondence to: M. E. Jenkin (atmos.chem@btinternet.com)

Received: 1 March 2015 - Published in Atmos. Chem. Phys. Discuss.: 31 March 2015

Revised: 16 September 2015 - Accepted: 23 September 2015 - Published: 16 October 2015

\begin{abstract}
The chemistry of isoprene degradation in the Master Chemical Mechanism (MCM) has been systematically refined and updated to reflect recent advances in understanding, with these updates appearing in the latest version, MCM v3.3.1. The complete isoprene degradation mechanism in MCM v3.3.1 consists of 1926 reactions of 602 closed shell and free radical species, which treat the chemistry initiated by reaction with $\mathrm{OH}$ radicals, $\mathrm{NO}_{3}$ radicals and ozone $\left(\mathrm{O}_{3}\right)$. A detailed overview of the updates is provided, within the context of reported kinetic and mechanistic information. The revisions mainly relate to the $\mathrm{OH}$-initiated chemistry, which tends to dominate under atmospheric conditions, although these include updates to the chemistry of some products that are also generated from the $\mathrm{O}_{3}$ - and $\mathrm{NO}_{3}$-initiated oxidation. The revisions have impacts in a number of key areas, including $\mathrm{HO}_{x}$ recycling, $\mathrm{NO}_{x}$ recycling and the formation of species reported to play a role in SOA (secondary organic aerosol)-formation mechanisms. The performance of the MCM v3.3.1 isoprene mechanism has been compared with those of earlier versions (MCM v3.1 and MCM v3.2) over a range of relevant conditions, using a box model of the tropical forested boundary layer. The results of these calculations are presented and discussed and are used to illustrate the impacts of the mechanistic updates in MCM v3.3.1.
\end{abstract}

\section{Introduction}

The degradation of emitted volatile organic compounds (VOCs) has a major influence on the chemistry of the troposphere, contributing to the formation of ozone $\left(\mathrm{O}_{3}\right)$, secondary organic aerosol (SOA) and other secondary pollutants (e.g. Haagen-Smit and Fox, 1954; Went, 1960; Andreae and Crutzen, 1997; Jenkin and Clemitshaw, 2000; Hallquist et al., 2009). Approximately $90 \%$ of organic material emitted globally is estimated to originate from biogenic sources (Guenther et al., 1995), with a major contribution from the reactive biogenic VOC, isoprene (2-methyl-buta-1,3-diene). In Europe, isoprene is estimated to contribute more than $30 \%$ of total biogenic VOC emissions, and $50 \%$ of reactive biogenic VOC emissions. Such estimates vary widely on a regional if not a global scale (e.g. Arneth et al., 2008; Warneke et al., 2010; Langner et al., 2014), but isoprene is believed to be the most abundantly emitted non-methane VOC in the atmosphere. The emission rate may also be altered by future changes to climate and other environmental factors (e.g. Peñuelas and Staudt, 2010; Arneth et al., 2010; Simpson et al., 2014, and references therein). Reliable representations of isoprene emissions and atmospheric oxidation are therefore essential components of chemistry-transport models (CTMs) applied to climate change and air quality assessments.

The potential impact of isoprene emission and oxidation on the composition of the global atmosphere has stimulated extensive study of its atmospheric chemistry, and there have been some notable advances in its understanding over the past decade. These developments include numerous labora- 
tory and theoretical studies of the kinetics and products of key elementary reactions, and elucidation and evaluation of mechanisms using chamber data (see references in Sect. 2), with additional information also resulting from the evaluation and intercomparison of mechanisms used in models (e.g. Archibald et al., 2010a, b; Stavrakou et al., 2010; Stone et al., 2011). The results of field studies have been used to test understanding of isoprene chemistry and to identify potential gaps in that understanding under atmospheric conditions. Such studies have stimulated or informed many of the recent laboratory, chamber and theoretical investigations, particularly in relation to missing recycling mechanisms for $\mathrm{HO}_{x}$ radicals (e.g. Tan et al., 2001; Thornton et al., 2002; Martinez et al., 2003; Ren et al., 2008; Lelieveld et al., 2008; Butler et al., 2008; Karl et al., 2009; Taraborrelli et al., 2012), the chemistry of oxidised organic nitrogen species (e.g. Horowitz et al., 2007; Perring et al., 2009) and the formation of species that contribute to SOA (e.g. Claeys et al., 2004; Chan et al., 2010; Froyd et al., 2010; Lin et al., 2013).

The Master Chemical Mechanism (MCM) provides a detailed description of atmospheric gas-phase organic chemistry that has been widely used by the atmospheric science community both directly and as a benchmark representation against which to develop and optimise reduced chemical mechanisms for use in CTMs. The MCM isoprene chemistry has been systematically revised and updated to reflect recent advances in understanding, with the updated mechanism provisionally released in March 2015 as MCM v3.3, as described in the "discussion" version of this paper (Jenkin et al., 2015). This has been further refined on the basis of a series of review comments, leading to the current finalised version, MCM v3.3.1. In this paper, a detailed overview of the updates is provided, within the context of reported kinetic and mechanistic information. The performance of the MCM v3.3.1 isoprene scheme has been examined for a range of relevant conditions, using a box model of the tropical forested boundary layer. The results of this study are presented and used to illustrate the impacts of the mechanistic updates in MCM v3.3.1.

\section{Updates to isoprene chemistry in MCM v3.3.1}

The complete degradation chemistry of isoprene, as represented in MCM v3.3.1, consists of 1926 reactions of 602 species and includes chemistry initiated by reaction with $\mathrm{OH}$, $\mathrm{O}_{3}$ and $\mathrm{NO}_{3}$. It can be viewed and downloaded using the subset mechanism assembling facility, available as part of the MCM website (http://mcm.leeds.ac.uk/MCM). The isoprene chemistry included previously in v3.1 (consisting of 605 reactions of 201 species) has been described in some detail by Pinho et al. (2005) and Archibald et al. (2010a), and the updates described below therefore document the major changes to the mechanism since MCM v3.1. These were partially implemented in MCM v3.2 (released in 2011), which con- tained 1428 reactions of 447 species. All those updates have been retained or further refined, with substantial additional revisions in the latest update to MCM v3.3.1. The revisions mainly relate to the $\mathrm{OH}$-initiated chemistry, which tends to dominate under atmospheric conditions, although these include updates to the chemistry of some products that are also generated from the $\mathrm{O}_{3}$ - and $\mathrm{NO}_{3}$-initiated oxidation. The revisions have impacts in a number of key areas, including $\mathrm{HO}_{x}$ recycling, $\mathrm{NO}_{x}$ recycling and the formation of species reported to play a role in SOA-formation mechanisms. The following subsections provide a detailed overview of the updates.

\subsection{Updates to the first-generation $\mathrm{OH}$-initiated chemistry}

\subsection{1 $\mathrm{OH}$ addition ratios and reactions of $\mathrm{OH}$-isoprene adducts with $\mathrm{O}_{2}$}

The initial stages of the chemistry following addition of $\mathrm{OH}$ to isoprene in the presence of $\mathrm{O}_{2}$, as represented in MCM v3.3.1, are shown in Fig. 1. In contrast to previous versions of the mechanism, the minor addition of $\mathrm{OH}$ to the central carbon atoms (i.e. at positions 2 and 3 ) is now represented, with respective addition ratios of 57.6, 4.2, 4.2 and $34.0 \%$ at positions 1, 2, 3 and 4. As described in more detail in Sect. 2.1.4 below (and in Sect. S1.1 of the Supplement), these were defined using a combination of structure-activity relationships (SARs) and optimisation of the first-generation mechanism to reported product yields. However, these addition ratios are fully consistent with those that have been reported in a number of theoretical studies (e.g. McGivern et al., 2000; Lei et al., 2000; Greenwald et al., 2007; Peeters et al., 2009).

The chemistry of the minor adducts formed from addition of $\mathrm{OH}$ to the central carbon atoms is based on the mechanism postulated in the theoretical study of Park et al. (2003). This involves isomerisation of the $\mathrm{OH}$-isoprene adducts to form $\alpha$-hydroxyalkenyl radicals, which each react with $\mathrm{O}_{2}$ to form $\mathrm{HO}_{2}$ and an unsaturated $\mathrm{C}_{5}$ carbonyl product. Addition of $\mathrm{OH}$ at position 2 thus leads to the exclusive formation of pent-4-en-2-one (PE4E2CO) and $\mathrm{HO}_{2}$ by this mechanism (see Fig. 1). Based on information reported in Park et al. (2003), addition of $\mathrm{OH}$ at position 3 is assumed to lead to competitive formation of both the isomeric unsaturated $\mathrm{C}_{5}$ carbonyl, 3-methyl-but-3-enal (ME3BU3ECHO), and $\mathrm{HO}_{2}$ via the isomerisation mechanism, and direct addition of $\mathrm{O}_{2}$ to the initial $\mathrm{OH}$-isoprene adduct to form a $\beta$-hydroxy peroxy radical (denoted ISOP34O2). As represented in MCM v3.3.1, this results in a total yield of unsaturated $\mathrm{C}_{5}$ carbonyls of $6.2 \%$, which is consistent with that reported by Zhao et al. (2004).

The chemistry following the major addition of $\mathrm{OH}$ to the terminal carbon atoms (i.e. at positions 1 and 4 ) has been substantially revised in MCM v3.3.1, and is based on the Leuven Isoprene Mechanism (LIM1) reaction framework reported in 


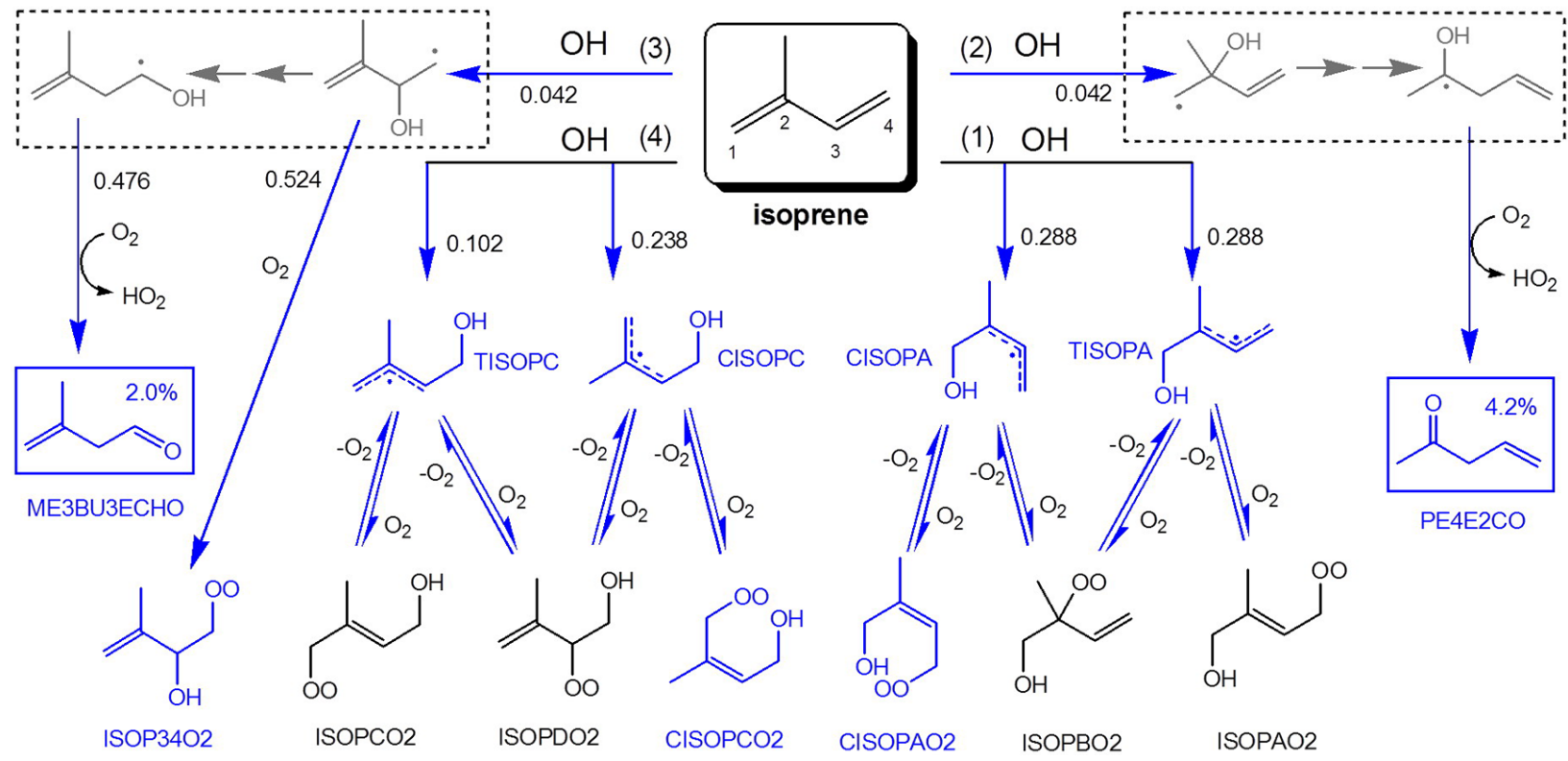

Figure 1. Schematic of the addition of $\mathrm{OH}$ to isoprene and the reactions of $\mathrm{OH}$-isoprene adducts with $\mathrm{O}_{2}$, as represented in $\mathrm{MCM}$ v3.3.1. Species in solid boxes are first-generation oxygenated end products, with their molar yields at $298 \mathrm{~K}$. Species and routes shown in blue are new in MCM v3.3.1. The chemistry in broken boxes is not included explicitly in the mechanism but is shown to clarify the routes to the corresponding products (see Park et al., 2003).

the theoretical studies of Peeters et al. (2009, 2014), as also shown in Fig. 1. In each case, $\mathrm{OH}$ addition leads to the formation of $E$ and $Z$ isomers of a hydroxyalkenyl radical possessing an allyl resonance. Reversible addition of $\mathrm{O}_{2}$ occurs at two possible sites in each resonant hydroxyalkenyl radical isomer, resulting in the formation of a $\beta$-hydroxy peroxy radical and $E$ and $Z$ isomers of a $\delta$-hydroxy peroxy radical (i.e. ISOPBO2, CISOPAO2 and ISOPAO2 from OH addition at carbon 1; and ISOPDO2, CISOPCO2 and ISOPCO2 from $\mathrm{OH}$ addition at carbon 4). The reversibility of $\mathrm{O}_{2}$ addition allows the peroxy radical population to be redistributed between the various isomers in each subset, such that the relative population of the peroxy radicals also depends on the prevailing rates of other removal processes for the peroxy radicals. As recommended in the review comment of Peeters (2015), the kinetic parameters applied to the $\mathrm{O}_{2}$ addition and peroxy radical back decomposition reactions are based on those calculated by Peeters et al. (2014), but with each increased by a factor of 5 on the basis of the experimental characterisation of the equilibration of peroxy radicals in each subset, as recently reported in preliminary form by Crounse et al. (2014). The resultant kinetic parameters are given in Table S1 in the Supplement.

\subsubsection{Peroxy radical reactions}

As with previous versions of the MCM (Jenkin et al., 1997; Saunders et al., 2003), the $\beta$ - and $\delta$-hydroxy peroxy radicals undergo bimolecular reactions with $\mathrm{NO}, \mathrm{NO}_{3}$ and $\mathrm{HO}_{2}$ and are also removed via reaction with the peroxy radical "pool" to represent the collective effect of peroxy radical self- and cross-reactions. Small revisions to the generic rate coefficients for the $\mathrm{NO}$ and $\mathrm{NO}_{3}$ reactions were implemented in MCM v3.2, and these are retained in MCM v3.3.1 (see Sect. 2.3). The rate coefficients for the other reactions remain based on the rules presented previously by Saunders et al. (2003).

Figure 2 shows the mechanisms following the (major) propagating channels of the reactions of the peroxy radicals with NO, involving the formation of the corresponding oxy radicals and their subsequent reactions to form first-generation oxygenated end products, which are discussed further in Sect. 2.1.3. Figure 2 also shows competing unimolecular isomerisation reactions that are newly implemented in MCM v3.3.1 for specific peroxy radical structures. As originally postulated by Peeters et al. (2009) and da Silva et al. (2010), 1,5 H atom shift isomerisation reactions are now represented for the $\beta$-hydroxy peroxy radicals, ISOPBO2 and ISOPDO2, leading to the respective formation of methyl vinyl ketone (MVK) and methacrolein (MACR), in conjunction with $\mathrm{HCHO}$ and $\mathrm{OH}$. The applied isomerisation rates are the LIM1 values calculated recently by Peeters et al. (2014), as presented in Table S1, with these also being generally consistent with those reported by da Silva et al. (2010).

Also based on the mechanism originally proposed by Peeters et al. (2009), the newly defined $Z$ isomers of the $\delta$ hydroxy peroxy radicals, CISOPAO2 and CISOPCO2, each undergoes a 1,6 $\mathrm{H}$ atom shift isomerisation reaction to pro- 


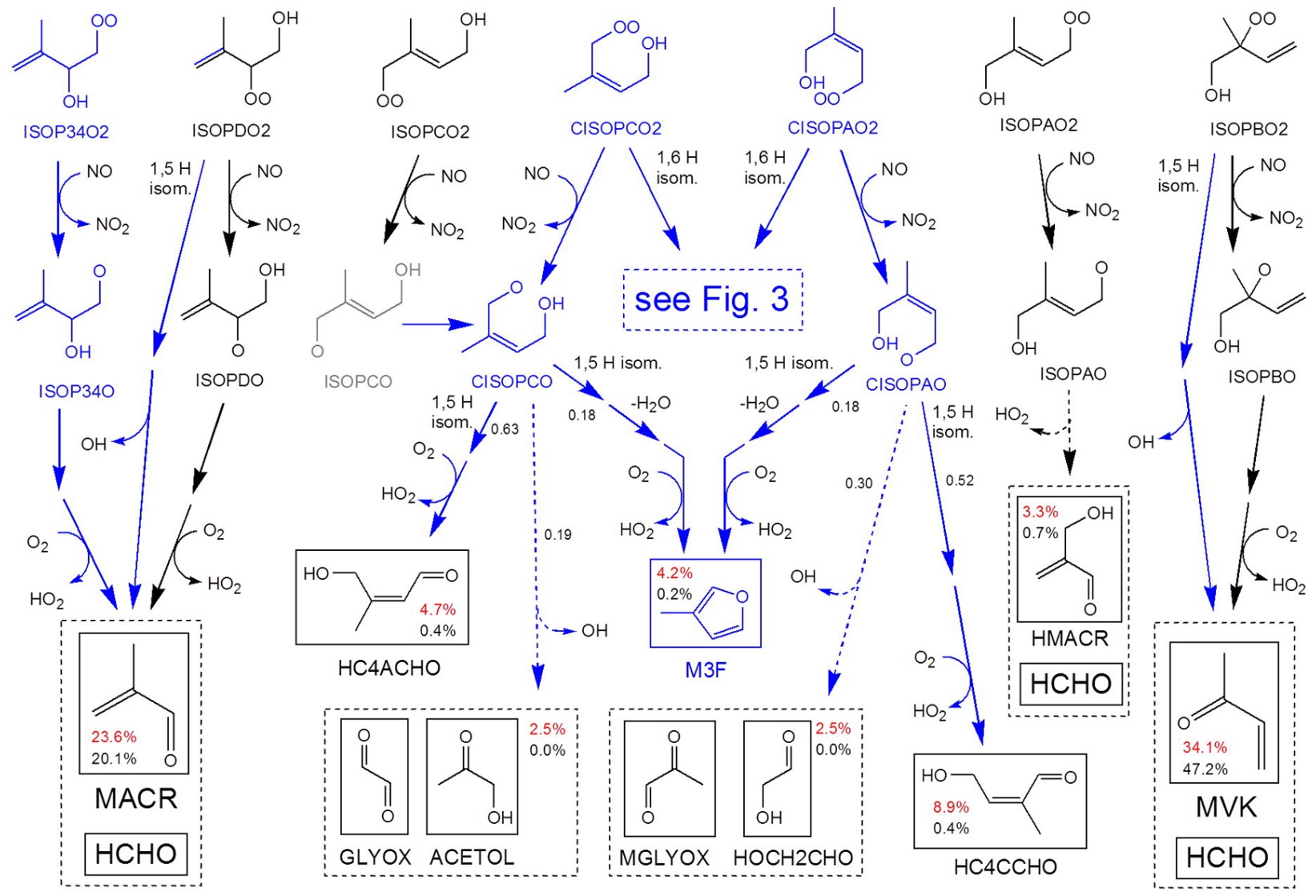

Figure 2. Schematic of the mechanisms following the propagating channels of the reactions of the first-generation $\beta$ - and $\delta$-hydroxy peroxy radicals with $\mathrm{NO}$, and competing unimolecular isomerisation reactions (see also Fig. 3). Species in solid boxes are the resultant firstgeneration oxygenated end products, with their associated molar yields at $10 \mathrm{ppm} \mathrm{NO}$ (in red) and $100 \mathrm{ppt} \mathrm{NO}$ (in black) at $298 \mathrm{~K}$ (see text and Fig. 4 for further details). HCHO has multiple sources, such that its total yield is $61.0 \%$ at $10 \mathrm{ppm} \mathrm{NO}$ and $68.0 \%$ at $100 \mathrm{ppt} \mathrm{NO}$. Species and routes shown in blue are new in MCM v3.3.1. Broken arrows indicate multistep mechanisms, involving the reactions of additional peroxy and oxy radicals (see Sect. 2.1.3 and Figs. S1-S3). The structure labelled ISOPCO is not included explicitly in the mechanism but is shown for clarity.

duce a resonant $\mathrm{C}_{5}$ hydroxy hydroperoxyalkenyl radical. As shown in Fig. 3, these are represented to react with $\mathrm{O}_{2}$ partially $(50 \%)$ via $\alpha$-hydroxy $\mathrm{H}$ atom abstraction to yield $\mathrm{HO}_{2}$ and the unsaturated hydroperoxyaldehyde products C5HPALD1 and C5HPALD2; with experimental evidence for the production of these products being reported by Crounse et al. (2011) and Berndt (2012). Based on the recent study of Peeters et al. (2014), the reactions of $\mathrm{O}_{2}$ with the hydroxy hydroperoxyalkenyl radicals are also represented to proceed equally via addition $\gamma$ to the $\mathrm{OH}$ group, leading to the production of the complex dihydroperoxy $\alpha$ formyl peroxy radicals, C536O2 and $\mathrm{C} 537 \mathrm{O} 2$ (see Fig. 3), these species being referred to as "di-HPCARPs" by Peeters et al. (2014). Under "low $\mathrm{NO}_{x}$ " conditions, $\mathrm{C} 536 \mathrm{O} 2$ and $\mathrm{C} 537 \mathrm{O} 2$ are represented to react significantly via $1,4 \mathrm{H}$ atom shift isomerisation reactions, for consistency with newly implemented chemistry for the methacrolein-derived $\alpha$-formyl peroxy radical, MACRO2 (see Sect. 2.2.1). This leads to significant formation of the dihydroperoxycarbonyl products
(DHPMEK and DHPMPAL) in conjunction with $\mathrm{OH}$ and $\mathrm{CO}$. The temperature-dependent rate expressions applied to the 1,6 $\mathrm{H}$ atom shift isomerisation reactions are based on those reported recently for LIM1 by Peeters et al. (2014) for CISOPAO2 and CISOPCO2, but scaled to recreate the phenomenological bulk isomerisation rate $\left(k_{\text {bulk }}\right)$ to form the unsaturated hydroperoxyaldehyde products (C5HPALD1 and C5HPALD2) for the conditions of the experiments reported by Crounse et al. (2011) (see Sect. S1.4 for further details). It is noted that further support for operation of the LIM reaction framework, optimised to the observations of Crounse et al. (2011), has been reported by Fuchs et al. (2013), based on measurements of $\mathrm{OH}$ and peroxy radicals during the chamber oxidation of isoprene.

The branching ratios applied to the propagating and terminating channels of the reactions of the $\beta$ - and $\delta$-hydroxy peroxy radicals with NO have been revised in MCM v3.3.1. The branching ratios to nitrate product formation from the terminating channels are assumed to be equivalent for the 


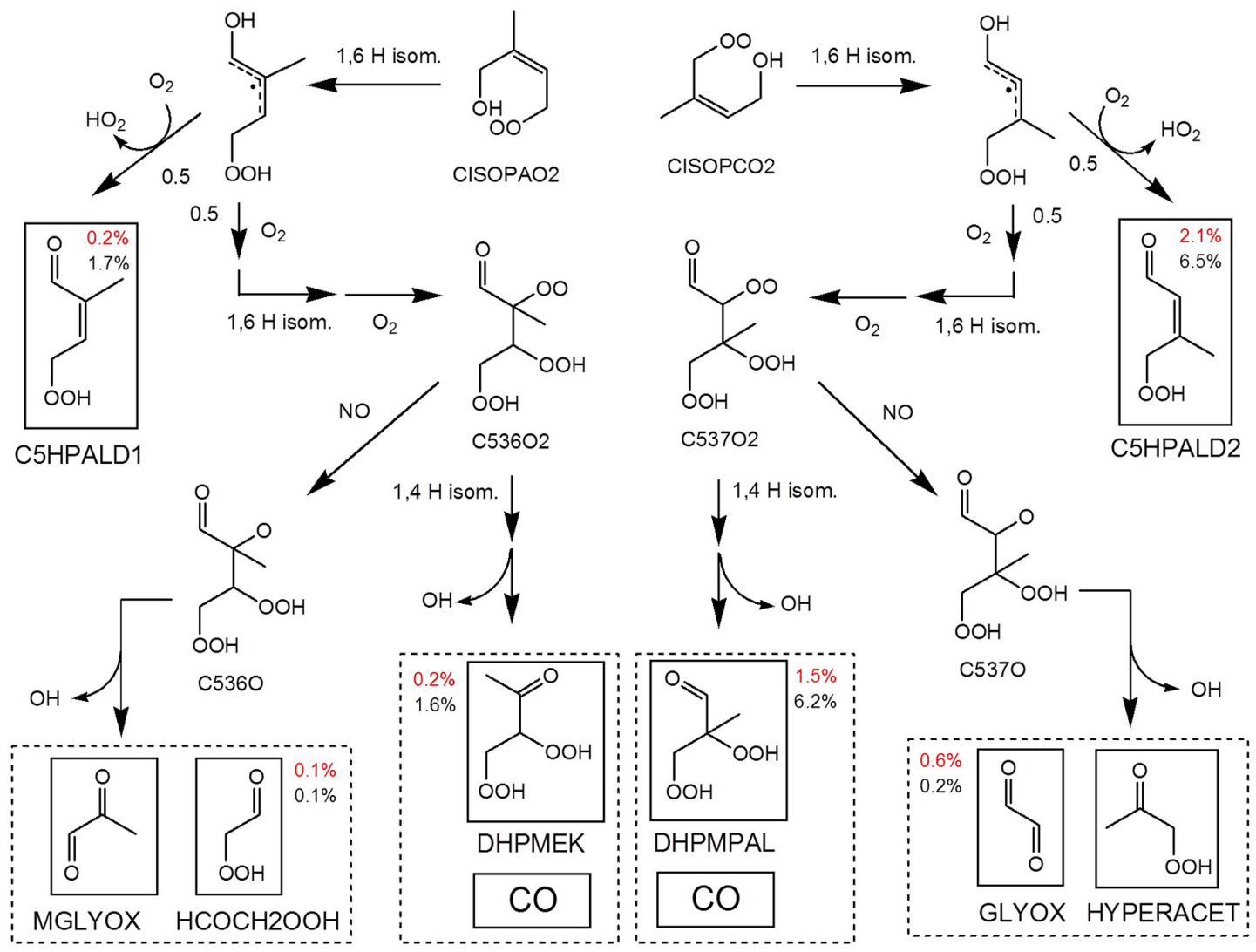

Figure 3. Schematic of the mechanisms following the 1,6 $\mathrm{H}$ atom shift isomerisation reactions of CISOPAO2 and CISOPCO2, as represented in MCM v3.3.1 (see also Fig. 2). As in Fig. 2, propagating channels of the reactions of NO with the intermediate peroxy radicals (C536O2 and C537O2), and competing unimolecular isomerisation reactions, are shown. Species in solid boxes are the resultant first-generation oxygenated end products, with their associated molar yields at 1 ppb NO (in red) and 100 ppt NO (in black) at $298 \mathrm{~K}$ (see text and Fig. 4 for further details). Note that GLYOX and MGLYOX are also formed via alternative routes, shown in Fig. 2.

secondary peroxy radical (ISOPDO2) and the tertiary peroxy radical (ISOPBO2), but the remaining (primary) peroxy radicals are assigned terminating channel ratios that are $20 \%$ lower. This reflects the well-established lower propensities of primary peroxy radicals to form nitrates (e.g. Carter and Atkinson, 1989; Lightfoot et al., 1992), which is also supported by the recent study of Teng et al. (2015) for hydroxyperoxy radicals formed from the reactions of $\mathrm{OH}$ with alkenes. The absolute values applied to the branching ratios were adjusted to result in an optimised total first-generation yield of nitrate products of $10 \%$ at the high [NO] limit (see Sect. 2.1.4). As discussed by Archibald et al. (2010a), this value was previously assigned on the basis of a chamber evaluation of reported yields and is in agreement with the current recommendation of the IUPAC Task Group on Atmospheric Chemical Kinetic Data Evaluation (http://iupac. pole-ether.fr/).

As with previous versions of the MCM, the reactions of the $\beta$ - and $\delta$-hydroxy peroxy radicals with $\mathrm{HO}_{2}$ proceed by a single channel producing a hydroxy-hydroperoxide product and $\mathrm{O}_{2}$. It is noted that some evidence for minor channels for the $\beta$-hydroxy peroxy radicals producing MVK (from ISOPBO2) and MACR (from ISOPDO2) has been reported (Paulot et al., 2009a; Liu et al., 2013; Navarro et al., 2013), with the implication that this results from a propagating channel also producing $\mathrm{OH}$ radicals. However, no direct evidence for $\mathrm{OH}$ formation from the reactions of $\mathrm{HO}_{2}$ with $\beta$ hydroxy peroxy radicals has been reported to date (e.g. Dillon et al., 2008), such that implementation of propagating channels awaits further experimental confirmation.

\subsubsection{Oxy radical reactions}

Figure 2 illustrates the reactions of the $\beta$ - and $\delta$-hydroxy oxy radicals, formed from propagating channels of the peroxy radical reactions, which lead to the formation of a number of first-generation oxygenated end products.

The well-established chemistry of the $\beta$-hydroxy oxy radicals, ISOPBO and ISOPDO, is essentially unchanged from previous versions of the MCM. These oxy radicals are thus represented to decompose by $\mathrm{C}-\mathrm{C}$ bond scission, leading to respective formation of MVK and MACR in conjunction 
with the $\mathrm{CH}_{2} \mathrm{OH}$ radical, which reacts with $\mathrm{O}_{2}$ to produce $\mathrm{HCHO}$ and $\mathrm{HO}_{2}$. The newly represented minor $\beta$-hydroxy oxy radical, ISOP34O, also decomposes to produce $\mathrm{HCHO}$ and a $\mathrm{C}_{4} \alpha$-hydroxyalkenyl radical, which reacts with $\mathrm{O}_{2}$ to form MACR and $\mathrm{HO}_{2}$ (see Fig. 2).

The propagating reactions of the $(E) \delta$-hydroxy peroxy radicals, ISOPAO2 and ISOPCO2, initially produce the (relatively minor) $E$ isomers of the corresponding $\delta$-hydroxy oxy radicals (denoted ISOPAO and ISOPCO in Fig. 2). As also previously represented in MCM v3.2, ISOPAO undergoes a rapid 1,5 $\mathrm{H}$ shift isomerisation reaction, leading to the ultimate formation of hydroxymethacrolein (HMACR), $\mathrm{HCHO}$ and $\mathrm{HO}_{2}$ via a multi-step mechanism involving a further $\mathrm{C}_{5}$ peroxy radical, as postulated by Dibble (2002) and Zhao et al. (2003) (see Fig. S3 and Sect. S1.3 for further details). Evidence for unsaturated $\mathrm{C}_{4}$ hydroxycarbonyl formation was subsequently reported by Zhao et al. (2004), consistent with formation of HMACR and/or isomeric products. It is noted that this fate for ISOPAO is not supported by the very recent study of Nguyen and Peeters (2015), who theoretically characterised the rapid conversion of both ISOPAO and ISOPCO into the corresponding $Z$ isomers (CISOPAO and CISOPCO), the chemistry of which is discussed below. The $1,5 \mathrm{H}$ shift chemistry of ISOPAO is currently retained, so that a route to the formation of HMACR as a minor product remains in MCM v3.3.1. In accordance with the results of Nguyen and Peeters (2015), however, exclusive isomerisation of ISOPCO into CISOPCO is represented in MCM v3.3.1, this reaction dominating over its alternative slow reaction with $\mathrm{O}_{2}$.

As shown in Fig. 2, a number of fates are included for the newly defined $Z$ isomers of the $\delta$-hydroxy oxy radicals, CISOPAO and CISOPCO. These are all initiated by a $1,5 \mathrm{H}$ atom shift isomerisation, to produce a resonant $\mathrm{C}_{5}$ dihydroxy alkenyl radical in each case, which is represented to react in three ways (see Figs. S1 and S2 and Sect. S1.2 for further details).

i. $\alpha$-hydroxy $\mathrm{H}$ atom abstraction, to yield $\mathrm{HO}_{2}$ and a $\mathrm{C}_{5}$ unsaturated hydroxyaldehyde product (i.e. $\mathrm{HC} 4 \mathrm{CCHO}$ or $\mathrm{HC} 4 \mathrm{ACHO}$ ). These reactions are required to account for the reported yields of $\mathrm{C}_{5}$ unsaturated hydroxyaldehydes (Zhao et al., 2004; Baker et al., 2005; Paulot et al., 2009b).

ii. Addition of $\mathrm{O}_{2} \gamma$ to the $\mathrm{OH}$ group, as postulated by Dibble (2004). This initiates sequences of reactions, involving $\mathrm{C}_{5} \alpha$-formyl peroxy radicals (C526O2 and $\mathrm{C} 527 \mathrm{O} 2$ ), leading to the ultimate formation of either methyl glyoxal (MGLYOX), glycolaldehyde (HOCH2CHO) and $\mathrm{OH}$ from CISOPAO, or glyoxal (GLYOX), hydroxyacetone (ACETOL) and $\mathrm{OH}$ from CISOPCO. The mechanism is based on that reported by Peeters and Nguyen (2012) (see Figs. S1 and S2). Evidence for minor formation of glyoxal, glycolaldehyde and hydroxyacetone (or subsets of these) as first- generation products has been reported in the chamber studies of Volkamer et al. (2006), Galloway et al. (2011) and Paulot et al. (2009b).

iii. Dehydration/cyclisation and subsequent reaction with $\mathrm{O}_{2}$, leading to the formation of 3-methylfuran (M3F) and $\mathrm{HO}_{2}$ by the mechanism postulated by FranciscoMárquez et al. (2003). These reactions are included to account for the reported minor formation of 3methylfuran in a number of studies (e.g. Atkinson et al., 1989; Paulson et al., 1992; Ruppert and Becker, 2000; Brégonzio-Rozier et al., 2015). The agreement of the yields of 3-methylfuran in those " $\mathrm{NO}_{x}$ present" studies, in conjunction with the reported time dependence of its production (e.g. Benkelberg et al., 2000; Lee et al., 2005), appear to indicate that it is formed (at least partially) as a first-generation product in the gas phase. However, it is noted that it is also likely formed by heterogeneous reactions of the $\mathrm{C}_{5}$ unsaturated hydroxyaldehyde products, $\mathrm{HC} 4 \mathrm{CCHO}$ and $\mathrm{HC} 4 \mathrm{ACHO}$ (Dibble, 2007), such that there are uncertainties in the contribution of its gas-phase formation.

\subsubsection{Optimisation of first-generation $\mathrm{OH}$-initiated chemistry}

As described in greater detail in Sect. S1 of the Supplement, the first-generation OH-initiated chemistry was optimised using reported product yields, with a number of constraints that have been described above in Sect. 2.1.1-2.1.3. Figure 4 shows the resultant calculated molar yields of the main products as a function of NO mixing ratio at $298 \mathrm{~K}$. These tend towards limiting values at the high end of the [NO] range shown, with little change at mixing ratios greater than about $500 \mathrm{ppb}$. This corresponds to conditions where reaction with $\mathrm{NO}$ is the dominant fate for all peroxy radicals in the system.

At lower [NO], the back decomposition reactions of the $\beta$ - and $\delta$-hydroxy peroxy radicals formed from $\mathrm{OH}$ addition at positions 1 and 4 (see Fig. 1) become increasingly competitive with the NO reactions, leading to a systematic variation in the relative peroxy radical population and a resultant impact on the product yields, as described in detail by Peeters et al. $(2009,2014)$. In addition to this, unimolecular isomerisation reactions also compete more effectively for specific peroxy radical structures. Under many atmospheric and chamber conditions, the reactions of peroxy radicals with $\mathrm{HO}_{2}$ and with the peroxy radical pool would also likely start to compete towards the low end of the displayed [NO] range in Fig. 3, although the extent of this competition depends on the absolute radical concentration. The impact of these reactions therefore requires simulation of specific atmospheric or chamber conditions and is not included in the illustration in Fig. 4.

The optimisation procedure primarily considered data from chamber studies performed with sufficient $\mathrm{NO}_{x}$ to cor- 


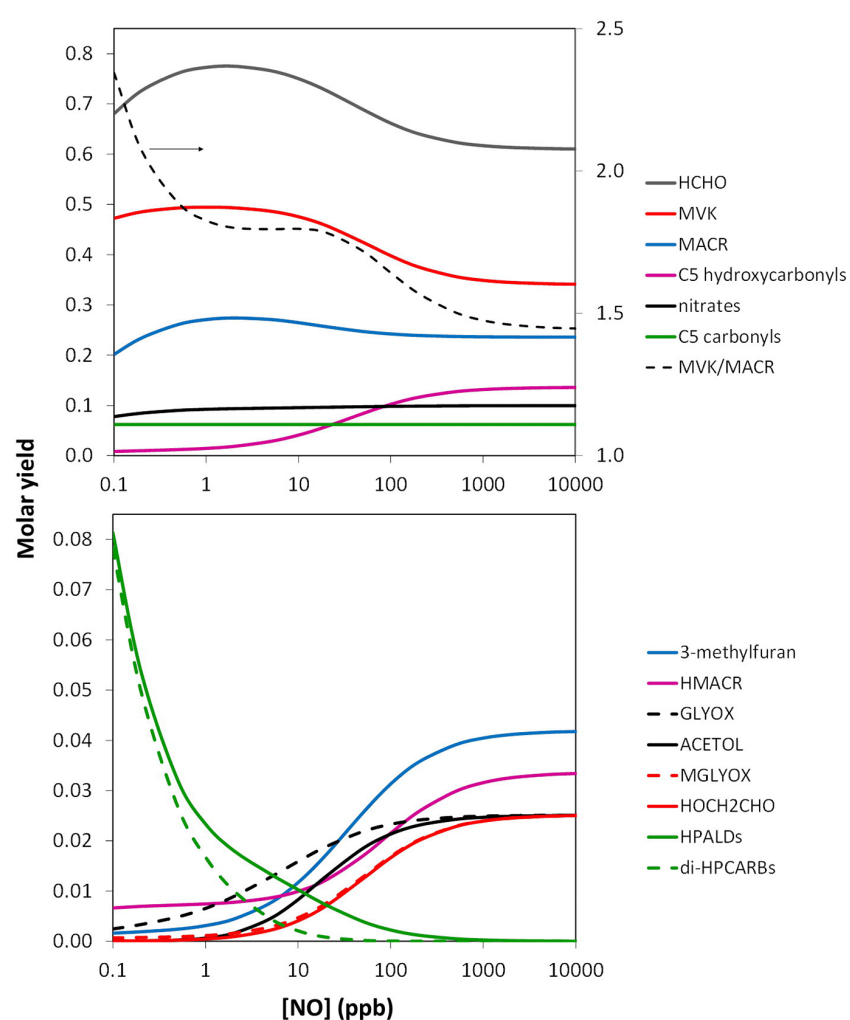

Figure 4. Molar yields of main first-generation products of the $\mathrm{OH}$-initiated oxidation of isoprene as a function of NO mixing ratio, at $298 \mathrm{~K}$, as represented in MCM v3.3.1 (see discussion in Sect. 2.1.4). $\mathrm{C}_{5}$ hydroxycarbonyls are $\mathrm{HC} 4 \mathrm{ACHO}$ and $\mathrm{HC} 4 \mathrm{CCHO}$; $\mathrm{C}_{5}$ carbonyls are PE4E2CO and ME3BU3ECHO; HPALDs are C5HPALD1 and C5HPALD2; di-HPCARBs are DHPMEK and DHPMPAL; and nitrates are as shown in Fig. 5. The broken line in the upper panel is the MVK/MACR yield ratio, as quantified on the right-hand scale.

respond to the high [NO] limit in Fig. 4, which is the majority of reported " $\mathrm{NO}_{x}$-present" studies. A number of parameters were varied to optimise the agreement in the calculated and reported product yields. These were the relative importance of $\mathrm{OH}$ attack at positions 1 and 4 in isoprene (which mainly influences the relative yields of MVK and MACR) and the relative importance of the three fates of the $Z$-isomers of the $\delta$-hydroxy oxy radicals, CISOPAO and CISOPCO, as described in Sect. 2.1.3 (which influences the formation of a number of the more minor first-generation products). This procedure resulted in generally good agreement between the reported yields and those calculated with $\mathrm{MCM} \vee 3.3 .1$ at the high [NO] limit (see Sect. S1 and Table S2 for full details).

The yields calculated for the major products $\mathrm{HCHO}$ $(61.0 \%)$, MVK $(34.1 \%)$ and MACR $(23.6 \%)$ at the high [NO] limit are therefore consistent with the respective reported yields of $(60.8 \pm 4.5) \%,(35.1 \pm 5.2) \%$ and $(23.6 \pm 2.8) \%$ in "high $\mathrm{NO}_{x}$ " studies (see Table S2). As shown in Fig. 4, the mechanism predicts an increase in the yields of these products at lower [NO], with maximum respective values of about 77,49 and $27 \%$ at about $1-2 \mathrm{ppb}$ NO. The relative yield of MVK and MACR generally increases with decreasing [NO], with the rapid increase at the low end of the scale being consistent with the preliminary results of Crounse et al. (2014), as discussed by Peeters (2015). However, it is noted that both the absolute yields of MVK (approaching $50 \%$ ) and MVK/MACR ratios $(\approx 1.8)$ are not fully consistent with those reported by Karl et al. (2006) and Liu et al. (2013), based on experiments carried out with NO mixing ratios of about 0.2 and $9 \mathrm{ppb}$, respectively. These studies both report MVK yields of about $41 \%$ and MVK/MACR ratios in the range 1.4-1.5 (i.e. similar to those at the high [NO] limit).

The yields of a number of minor products formed wholly or partially from the reactions of CISOPAO and CISOPCO were also optimised to be consistent with reported studies at the high [NO] limit (see Table S2). These are the $\mathrm{C}_{5}$ hydroxycarbonyls (HC4ACHO and $\mathrm{HC} 4 \mathrm{CCHO}$ ), 3-methylfuran, glyoxal/hydroxyacetone and methyl glyoxal/glycolaldehyde. As shown in Fig. 4, the yields of all these products are predicted to decrease as [NO] is lowered. In the cases of the $\mathrm{C}_{5}$ hydroxycarbonyls and 3-methylfuran, this is due to the decreased production of CISOPAO and CISOPCO that results from a combination of the increased operation of the isomerisation reactions for the precursor peroxy radicals (CISOPAO2 and CISOPCO2) and the general redistribution of the peroxy radical population (Peeters et al., 2014). For glyoxal/hydroxyacetone and methyl glyoxal/glycolaldehyde, however, the yields are predicted to be particularly sensitive to [NO], with complete inhibition of their formation from CISOPAO and CISOPCO at the low end of the [NO] range. In addition to the decreased production of CISOPAO and CISOPCO, their formation is also influenced by the chemistry of the $\alpha$-formyl peroxy radicals (C526O2 and $\mathrm{C} 527 \mathrm{O} 2$ ), as formed in the mechanism theoretically characterised by Peeters and Nguyen (2012) and applied here (see Figs. S1 and S2). As discussed further below (Sects. 2.2.1 and 2.2.3), 1,4 $\mathrm{H}$ atom shift isomerisation reactions are included for $\mathrm{C} 526 \mathrm{O} 2$ and $\mathrm{C} 527 \mathrm{O} 2$, for consistency with newly implemented chemistry for the methacrolein-derived $\alpha$-formyl peroxy radical, MACRO2, as also suggested by Peeters and Nguyen (2012). These isomerisation reactions compete more effectively as [NO] is lowered, thereby inhibiting formation of glyoxal/hydroxyacetone and methyl glyoxal/glycolaldehyde.

As indicated above in Sect. 2.1.2, the total yield of firstgeneration organic nitrates was assigned a value of $10 \%$ at the high [NO] limit, based on the results of a previous chamber evaluation (Pinho et al., 2005) and the IUPAC Task Group recommendation, with this also being consistent with the range of the reported values (see Table S2). This total includes contributions from five isomeric hydroxynitrates (ISOPANO3, ISOPBNO3, ISOPCNO3, ISOPDNO3 and ISOP34NO3) and additional minor contributions from a 

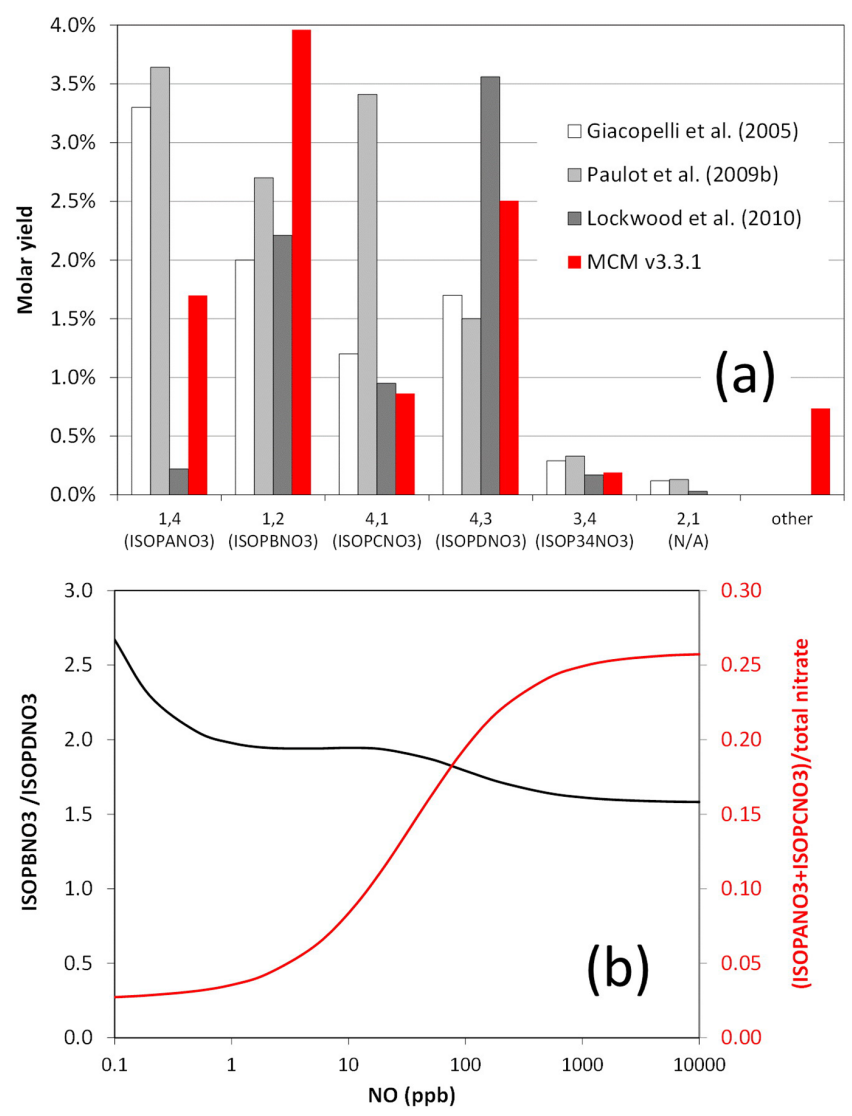

Figure 5. (a) Reported molar yields of speciated nitrate products formed from the first-generation $\mathrm{OH}$-initiated oxidation of isoprene (see Fig. 7 for structures). The " 1,4 " and " 4,1 " categories include contributions from both $E$ and $Z$ isomers, where reported. The MCM v3.3.1 values correspond to $298 \mathrm{~K}$ at the high [NO] limit (see Fig. 3), with the total yield being $10 \%$. The "other" category includes C524NO3 (formed in the mechanism to HMACR formation), C526NO3 (formed in the mechanism to methyl glyoxal/glycolaldehyde formation) and C527NO3 (formed in the mechanism to glyoxal/hydroxyacetone formation). The " 2,1 " isomer is not formed in MCM v3.3.1. (b) [NO] dependences of the ratio of the $\beta$-hydroxy isomers (ISOPBNO3 / ISOPDNO3) and the fractional contribution of the $\delta$-hydroxy isomers (ISOPANO 3 and ISOPCNO3). The displayed [NO] range corresponds to values of $k_{\text {tr }}$ in the approximate range $0.022-2200 \mathrm{~s}^{-1}$.

further three species formed in the mechanisms generating hydroxymethacrolein (C524NO3), glyoxal/hydroxyacetone (C527NO3) and methyl glyoxal/glycolaldehyde (C526NO3) (see Fig. 5a). Compared with MCM v3.2, the main consequence of the revised branching ratios applied to the individual peroxy radical isomers in MCM v3.3.1 (described in Sect. 2.1.2) is an increased contribution of the tertiary $\beta$ hydroxynitrate (ISOPBNO3) and a decreased contribution of the secondary $\beta$-hydroxynitrate (ISOPDNO3). The resultant relative contributions of these $\beta$-hydroxy isomers, and the fractional contribution of the $\delta$-hydroxy isomers
(ISOPANO3 and ISOPCNO3) at the high [NO] limit (shown in Fig. 5b) are consistent with the preliminary results of Crounse et al. (2014). However, the distribution does not appear to match the results of any of the previously reported studies (Giacopelli et al., 2005; Paulot et al., 2009b; Lockwood et al., 2010), which display some variability (Fig. 5a). The mechanism predicts a slight decrease in the total firstgeneration nitrate yield as [NO] is lowered, falling to about $8 \%$ at the low end of the considered range (see Fig. 4). This results mainly from the impact of competing isomerisation reactions for selected peroxy radicals. The associated [NO] dependences of the $\beta$-hydroxy isomer ratio, and the $\delta$-hydroxy isomer contribution, are consistent with the preliminary results of Crounse et al. (2014) (see Fig. 5b).

Figure 4 also illustrates the increasing formation of the unsaturated hydroperoxyaldehydes (C5HPALD1 and C5HPALD2) and the dihydroperoxycarbonyls (DHPMEK and DHPMPAL) as [NO] decreases, these species being formed from the chemistry initiated by the $1,6 \mathrm{H}$ atom shift isomerisation reactions of CISOPAO2 and CISOPCO2 (see Fig. 3), within the LIM1 reaction framework (Peeters et al., 2014). As indicated above (Sect. 2.1.2), the formation of the unsaturated hydroperoxyaldehydes was optimised to recreate the phenomenological bulk isomerisation rate $\left(k_{\mathrm{bulk}}\right)$ reported by Crounse et al. (2011), which was about $0.002 \mathrm{~s}^{-1}$ at $295 \mathrm{~K}$, under conditions when the peroxy radical loss rate through bimolecular reactions $\left(k_{\mathrm{tr}}\right)$ was $\approx 0.021 \mathrm{~s}^{-1}$ (see Sect. S1.4 and Fig. S4 for further details). As shown in Fig. 3, the chemistry initiated by the $1,6 \mathrm{H}$ atom shift isomerisation reactions also provides additional first-generation routes to methyl glyoxal and (particularly) glyoxal, which are most effective at intermediate [NO], when the reactions of NO with the $\alpha$-formyl peroxy radicals $\mathrm{C} 536 \mathrm{O} 2$ and $\mathrm{C} 537 \mathrm{O} 2$ can compete with their $1,4 \mathrm{H}$ atom shift isomerisation reactions. Evidence for operation of these routes has been reported by Crounse et al. (2012a), through detection of the hydroperoxycarbonyl co-products, HCOCH2OOH and HYPERACET (see Fig. 3).

Although not specifically optimised, the mechanism predicts a yield of hydroxymethacrolein (HMACR) of $3.3 \%$ at the high [NO] limit, which is consistent with the yield of $\mathrm{C}_{4}$ hydroxycarbonyls of $(3.3 \pm 1.6) \%$ reported by Zhao et al. (2004). This shows a modest variation with [NO], resulting mainly from the redistribution of the peroxy radical population (see Fig. 4). As indicated above (Sect. 2.1.1), the yield of unsaturated $\mathrm{C}_{5}$ carbonyls $(6.2 \%)$ also agrees well with the yield of $(8.4 \pm 2.4) \%$ reported by Zhao et al. (2004). This shows no variation with [NO] because the unsaturated $\mathrm{C}_{5}$ carbonyls are formed following prompt isomerisation of the minor $\mathrm{OH}$-isoprene adducts, formed from $\mathrm{OH}$ addition at positions 2 and 3 in isoprene (see Fig. 1). 


\subsection{Updates to the higher-generation chemistry}

\subsubsection{Methacrolein (MACR)}

Figure 6 shows the main features of the chemistry following the reaction of $\mathrm{OH}$ with $\mathrm{MACR}$, with the newly implemented updates in MCM v3.3.1 highlighted. These are as follows:

i. A competitive $1,4 \mathrm{H}$ atom shift isomerisation reaction is now included for the $\alpha$-formyl peroxy radical, $\mathrm{MACRO}$, formed from the major $\mathrm{OH}$ addition channel, resulting in the direct formation of hydroxyacetone, $\mathrm{CO}$ and $\mathrm{OH}$. This reaction was proposed and characterised by Crounse et al. (2012b), and the applied temperaturedependent rate coefficient is based on their reported value (see Table S3), with additional support deriving from the recent chamber study of Fuchs et al. (2014). For consistency, 1,4 $\mathrm{H}$ atom shift isomerisation reactions have also been included for a number of other $\alpha$-formyl peroxy radicals. These include HMACRO2 (formed analogously from the reaction of $\mathrm{OH}$ with hydroxymethacrolein, HMACR) and the $\mathrm{C}_{5}$ peroxy radicals, $\mathrm{C} 57 \mathrm{O} 2$ and $\mathrm{C} 58 \mathrm{AO} 2$, which have a number of sources in the isoprene mechanism, including the analogous reactions of $\mathrm{OH}$ with unsaturated $\mathrm{C}_{5}$ hydroxy carbonyls ( $\mathrm{HC} 4 \mathrm{CCHO}$ and $\mathrm{HC} 4 \mathrm{ACHO}$, respectively), and the reaction of $\mathrm{OH}$ with the major isoprene epoxydiol (IEPOXB), as described further in Sect. 2.2.3. They also include the complex $\alpha$-formyl peroxy radicals, $\mathrm{C} 526 \mathrm{O} 2$ and $\mathrm{C} 527 \mathrm{O} 2$ (formed in the newly implemented firstgeneration chemistry forming glyoxal/hydroxyacetone and methylglyoxal/glycolaldehyde, as discussed above in Sects. 2.1.3 and 2.1.4 and shown in Figs. S1 and S2) and the "di-HPCARPs", C536O2 and $\mathrm{C} 537 \mathrm{O} 2$ (formed following the 1,6 $\mathrm{H}$ atom shift isomerisation reactions of CISOPAO2 and CISOPCO2, as discussed in Sect. 2.1.2 and shown in Fig. 3).

ii. The products of the reaction of $\mathrm{OH}$ with methacryloyl peroxy nitrate (MPAN) have been updated on the basis of the studies of Kjaergaard et al. (2012) and Lin et al. (2013). As shown in Fig. 6, the reaction now has significant channels forming hydroxymethyl-methyl- $\alpha$ lactone (HMML) and methacrylic acid epoxide (MAE), in conjunction with release of $\mathrm{NO}_{3}$ radicals. HMML and MAE have been postulated by the above authors to play a role in SOA-formation mechanisms, through efficient reactive uptake on acidic aerosol particles to form condensed-phase 2-methylglyceric acid. The representation of heterogeneous chemistry is outside the scope of MCM v3.3.1, but their gas-phase removal via reactions with $\mathrm{OH}$ is represented (see Sect. 2.2.7).

iii. The products of the reaction of $\mathrm{OH}$ with methacrylic peroxy acid $(\mathrm{MACO} 3 \mathrm{H})$ have been updated on the basis of the study of Kjaergaard et al. (2012). As shown in Fig. 6, the reaction now has a major channel forming hydroxyacetone and $\mathrm{CO}$, and a minor channel forming HMML, in conjunction with release of $\mathrm{OH}$ radicals in each case. The products of the reactions of $\mathrm{OH}$ with a number of structurally similar peroxy acids have also been updated to include major $\mathrm{OH}$-forming channels. These include $\mathrm{HMACO} 3 \mathrm{H}$, formed from hydroxymethacrolein (HMACR) oxidation; and $\mathrm{HC} 4 \mathrm{ACO} 3 \mathrm{H}$ and $\mathrm{HC} 4 \mathrm{CCO} 3 \mathrm{H}$, formed from the oxidation of the unsaturated $\mathrm{C}_{5}$ hydroxycarbonyls, $\mathrm{HC} 4 \mathrm{ACHO}$ and $\mathrm{HC} 4 \mathrm{CCHO}$. In these cases, however, $\mathrm{OH}$ formation is represented to occur exclusively in conjunction with $\mathrm{CO}$ and the corresponding dihydroxycarbonyl product, such that the minor channels forming products analogous to HMML are not currently represented.

\subsubsection{Nitrates}

Substantial revisions to the further degradation chemistry of the first-generation nitrate products were previously implemented in MCM v3.2, which included the chemistry initiated by reactions with both $\mathrm{OH}$ and $\mathrm{O}_{3}$, and photolysis. These generally followed the rules in the MCM schemewriting protocol (Jenkin et al., 1997; Saunders et al., 2003), but without the major simplifications previously applied to oxidised organic nitrogen species. The treatment also made use of the structure-activity relationship (SAR) method of Vereecken and Peeters (2009) to estimate the impacts of the nitrate groups $\left(-\mathrm{ONO}_{2}\right)$ on the reactions of the intermediate oxy radicals and took account of information in a number of experimental studies (e.g. Paulot et al., 2009b; Lockwood et al., 2010) in defining parameters for specific reactions. The update added about 400 reactions of over 100 species to the mechanism. The majority of this chemistry has been retained unchanged in MCM v3.3.1, although selected important updates have been implemented, based on the results of more recent studies (e.g. Suarez-Bertoa et al., 2012; Lee et al., 2014; Müller et al., 2014).

The rate coefficients for the initiation reactions with $\mathrm{OH}$ and $\mathrm{O}_{3}$ have been revised to take account of the recent study of Lee et al. (2014), leading to a notable reduction in the importance of the $\mathrm{O}_{3}$-initiated chemistry compared with $\mathrm{MCM}$ v3.2. Representative average atmospheric lifetimes for the first-generation nitrates with respect to these reactions are estimated to be about $8.5 \mathrm{~h}$ (for $[\mathrm{OH}]=10^{6}$ molecule $\mathrm{cm}^{-3}$ ) and 9.4 days (for $20 \mathrm{ppb} \mathrm{O}_{3}$ ), based on the nitrate distribution calculated at $1 \mathrm{ppb} \mathrm{NO}$. Because of the [NO] dependence of the first-generation chemistry discussed above, it should be noted that the distribution of nitrates varies with conditions, such that the corresponding average lifetimes are about $5 \mathrm{~h}$ and 2 days for the distribution calculated at the high [NO] limit, which contains a greater proportion of the more reactive 1,4- and 4,1-substituted species, ISOPANO3 and ISOPCNO3. 


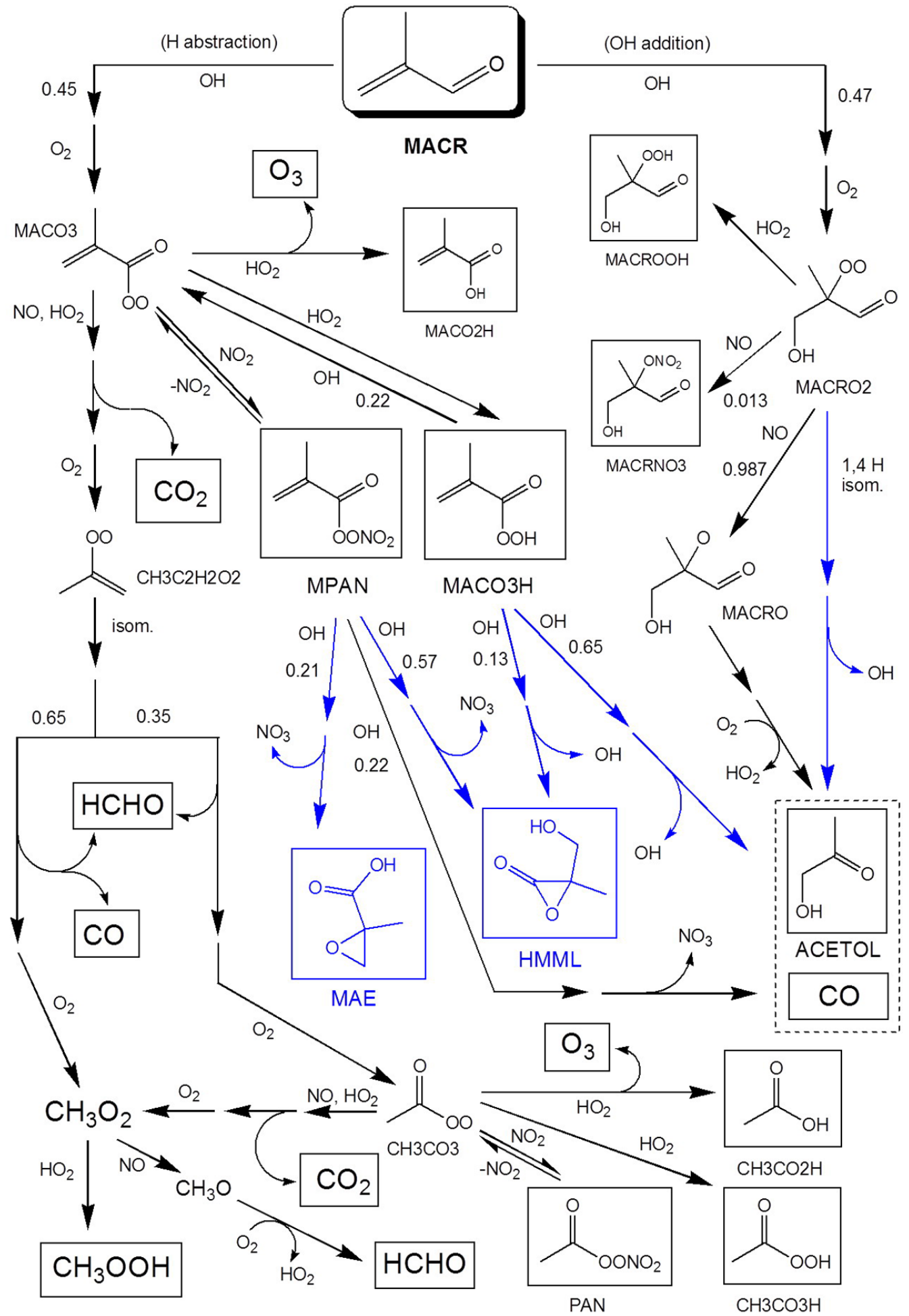

Figure 6. Schematic of the main features of the mechanism following reaction of $\mathrm{OH}$ with methacrolein (MACR), as represented in MCM v3.3.1. For clarity, the chemistry of the minor $(8 \%) \mathrm{OH}$ addition channel and the reactions of the intermediate peroxy radicals with $\mathrm{NO}_{3}$ and the peroxy radical pool are not shown. Species in solid boxes are oxygenated end products. Species and routes shown in blue are new in MCM v3.3.1. The further chemistry of MPAN and MACO3H is also shown to illustrate newly implemented updates. 

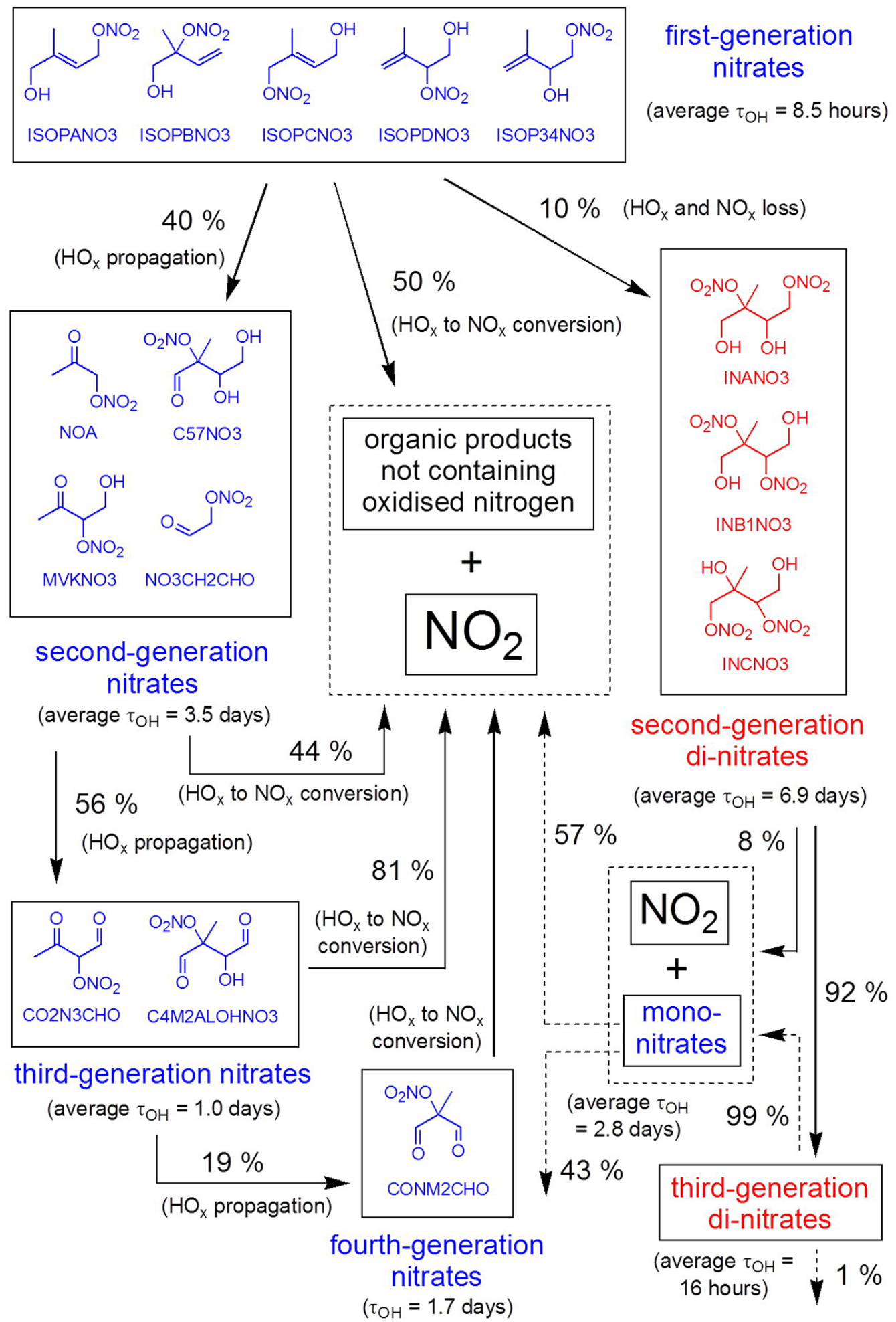

Figure 7. Overview of the $\mathrm{OH}$-initiated degradation of the first-generation nitrates in MCM v3.3.1, based on the calculated distribution at 1 ppb NO. Products with one nitrate group are shown in blue, and those with two nitrate groups are shown in red. Where sets of species are shown, these collectively account for $\geq 90 \%$ of the nitrate yield in the given category. Representative average lifetimes $\left(\tau_{\mathrm{OH}}\right)$ for reactions of the groups of products with $\mathrm{OH}$ are shown, based on $[\mathrm{OH}]=10^{6}$ molecule $\mathrm{cm}^{-3}$. 
A general overview of the $\mathrm{OH}$-initiated chemistry over several generations is illustrated in Fig. 7. An important feature of the degradation chemistry is the extent to which the organic products retain the nitrate group, whether $\mathrm{NO}_{x}$ is released, or whether additional $\mathrm{NO}_{x}$ is sequestered to form dinitrate products. Figure 7 shows that about $40 \%$ of the second-generation products formed from the $\mathrm{OH}$-initiated chemistry retain the nitrate group (in conjunction with $\mathrm{HO}_{x}$ propagation), with about $50 \%$ leading to the release of $\mathrm{NO}_{x}$ in the form of $\mathrm{NO}_{2}$ (in conjunction with $\mathrm{HO}_{x}$ loss). A small fraction $(10 \%)$ is estimated to generate dinitrate products, with these processes leading to loss of both $\mathrm{NO}_{x}$ and $\mathrm{HO}_{x}$. These proportions are broadly consistent with the product yields reported by Lee et al. (2014) for the OH-initiated oxidation of selected first-generation nitrate isomers, and also with constraints on the lifetimes and the extent of nitrate group recycling derived from atmospheric observations in the continental USA (Perring et al., 2009). Figure 7 also demonstrates that the subsequent generations of product have generally longer lifetimes with respect to reaction with $\mathrm{OH}$ than the first-generation nitrates but with progressively greater proportions of $\mathrm{NO}_{x}$ being released at each oxidation step. For simplicity, the illustration in Fig. 7 assumes that the level of NO is sufficiently high that the reactions of intermediate peroxy radicals with $\mathrm{HO}_{2}$ and the peroxy radical pool are of minor importance. The participation of these reactions tends to increase the proportion of nitrate-retaining products, owing to the greater importance of terminating reaction channels that preclude release of $\mathrm{NO}_{x}$, e.g. the formation of multifunctional hydroperoxynitrates from the reactions with $\mathrm{HO}_{2}$.

The representation of the $\mathrm{O}_{3}$-initiated chemistry also results in only partial release of $\mathrm{NO}_{x}$ in the initial oxidation step, with about $65 \%$ formation of second-generation products that retain the nitrate group. Once again, this is consistent with the product yields reported by Lee et al. (2014) for the $\mathrm{O}_{3}$-initiated oxidation of selected first-generation nitrate isomers. The identities of the major nitrate-containing products overlap substantially with those generated from the $\mathrm{OH}$ initiated chemistry, such that the subsequent $\mathrm{OH}$-initiated oxidation and $\mathrm{NO}_{x}$ release follows a similar pattern to that shown in Fig. 7. By analogy with the ozonolysis of simple alkenes, the $\mathrm{O}_{3}$-initiated chemistry is also currently estimated to generate $\mathrm{OH}$ radicals with an average yield of about $50 \%$, although this is somewhat higher than reported by Lee et al. (2014) for selected isomers.

The mechanism also includes photolysis reactions for the first-generation nitrates, and for many of the multifunctional nitrate products formed from the $\mathrm{OH}$ - and $\mathrm{O}_{3}$-initiated chemistry. The majority of these higher-generation nitrate products contain $\alpha$ - or $\beta$-carbonyl groups (e.g. all the mononitrate species shown in Fig. 7), and the representation of their photolysis in MCM v3.3.1 has been updated on the basis of the recent study of Müller et al. (2014) and the discussion comment of Müller (2015), leading to associated clear sky lifetimes in the range of $1-10 \mathrm{~h}$ (for solar zenith angle = $30^{\circ}$ ). As a result, photolysis is now the major fate in most cases, leading to quantitative release of $\mathrm{NO}_{x}$ in the form of $\mathrm{NO}_{2}$, in conjunction with $\mathrm{HO}_{x}$ formation. This tends to inhibit formation of the third- and fourth-generation mononitrate products shown in Fig. 7 and results in substantial $\mathrm{NO}_{x}$ regeneration from the second-generation species. The thirdgeneration dinitrate species also generally contain carbonyl groups $\alpha$ to at least one nitrate group and therefore photolyse efficiently. This leads about equally to the formation of either $\mathrm{NO}_{2}, \mathrm{HO}_{x}$ and mononitrate products, or the release of two molecules of $\mathrm{NO}_{2}$ in conjunction with organic products not containing a nitrate group.

\subsubsection{Hydroperoxides and epoxydiols}

The chemistry of the first-generation hydroxyhydroperoxides was also substantially revised in MCM v3.2 to represent dominant formation of isomeric epoxydiol products, with associated prompt regeneration of $\mathrm{OH}$, as characterised by Paulot et al. (2009a). The epoxydiols are believed to play and important role in the formation of SOA from isoprene (Paulot et al., 2009a; Lin et al., 2011), and have been detected in ambient samples (e.g. Chan et al., 2010; Froyd et al., 2010). A provisional representation of the gas-phase degradation of the epoxydiols was also included in MCM v3.2. This chemistry has been updated in MCM v3.3.1, mainly based on the results of the recent study of Bates et al. (2014).

Figure 8 shows an overview of the degradation mechanism following reaction of $\mathrm{OH}$ with the five isomeric isoprene hydroxy-hydroperoxides included in MCM v3.3.1. They are estimated to react rapidly with $\mathrm{OH}$, leading to atmospheric lifetimes in the approximate range of $2-6 \mathrm{~h}$, for $[\mathrm{OH}]=10^{6}$ molecule $\mathrm{cm}^{-3}$. Under representative "low $\mathrm{NO}_{x}$ " conditions (based on the peroxy radical distribution at the low end of the [NO] range in Fig. 4), the MCM v3.3.1 representation results in the formation of the isomeric epoxydiols (IEPOXA, IEPOXB and IEPOXC) with a collective yield of about $85 \%$, which is consistent with that reported by Paulot et al. (2009a). This is dominated by IEPOXB (accounting for about $95 \%$ of the total), this isomer being formed from the two most abundant hydroxyhydroperoxides, ISOPBOOH and ISOPDOOH (see Fig. 8). This is also consistent with the distribution of the epoxydiol isomers reported by Bates et al. (2014).

The epoxydiols are removed by reaction with $\mathrm{OH}$, with rate coefficients based on those reported by Bates et al. (2014) for IEPOXC and cis- and trans- isomers of IEPOXB, leading to associated atmospheric lifetimes of about 1 day. It is noted that Jacobs et al. (2013) reported somewhat higher rate coefficients for the reactions of $\mathrm{OH}$ with IEPOXA and the trans- isomer of IEPOXB, consistent with atmospheric lifetimes of about $8 \mathrm{~h}$. The rate coefficients of Bates et al. (2014) are currently adopted in MCM v3.3.1, because they allow a broadly consistent representation of the 


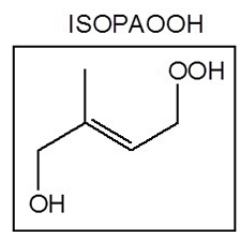

$\tau_{\mathrm{OH}}=1.8$ hours

$\mathrm{OH} \longrightarrow 0.93$<smiles>C[C@H]1C[C@@H]1O</smiles>

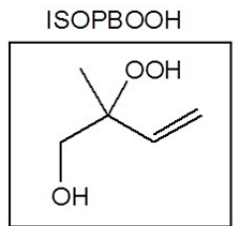

$\tau_{\mathrm{OH}}=5.6$ hours

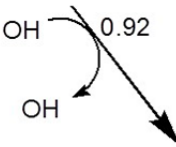

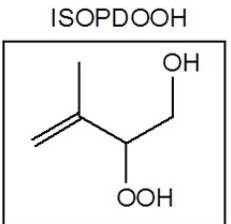

$\tau_{\mathrm{OH}}=2.4$ hours

$0.75-\mathrm{OH}$

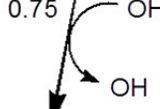

IEPOXB

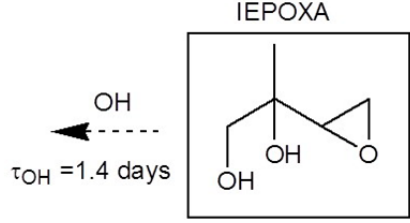

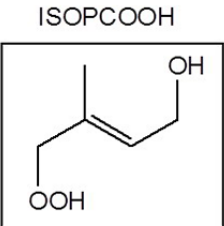

$\tau_{\mathrm{OH}}=1.8$ hours

$\mathrm{OH} \longrightarrow 0.93$

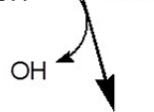

IEPOXC

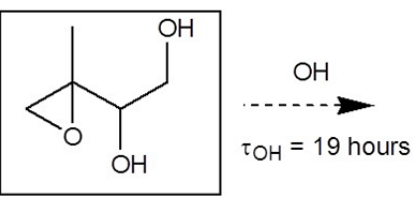

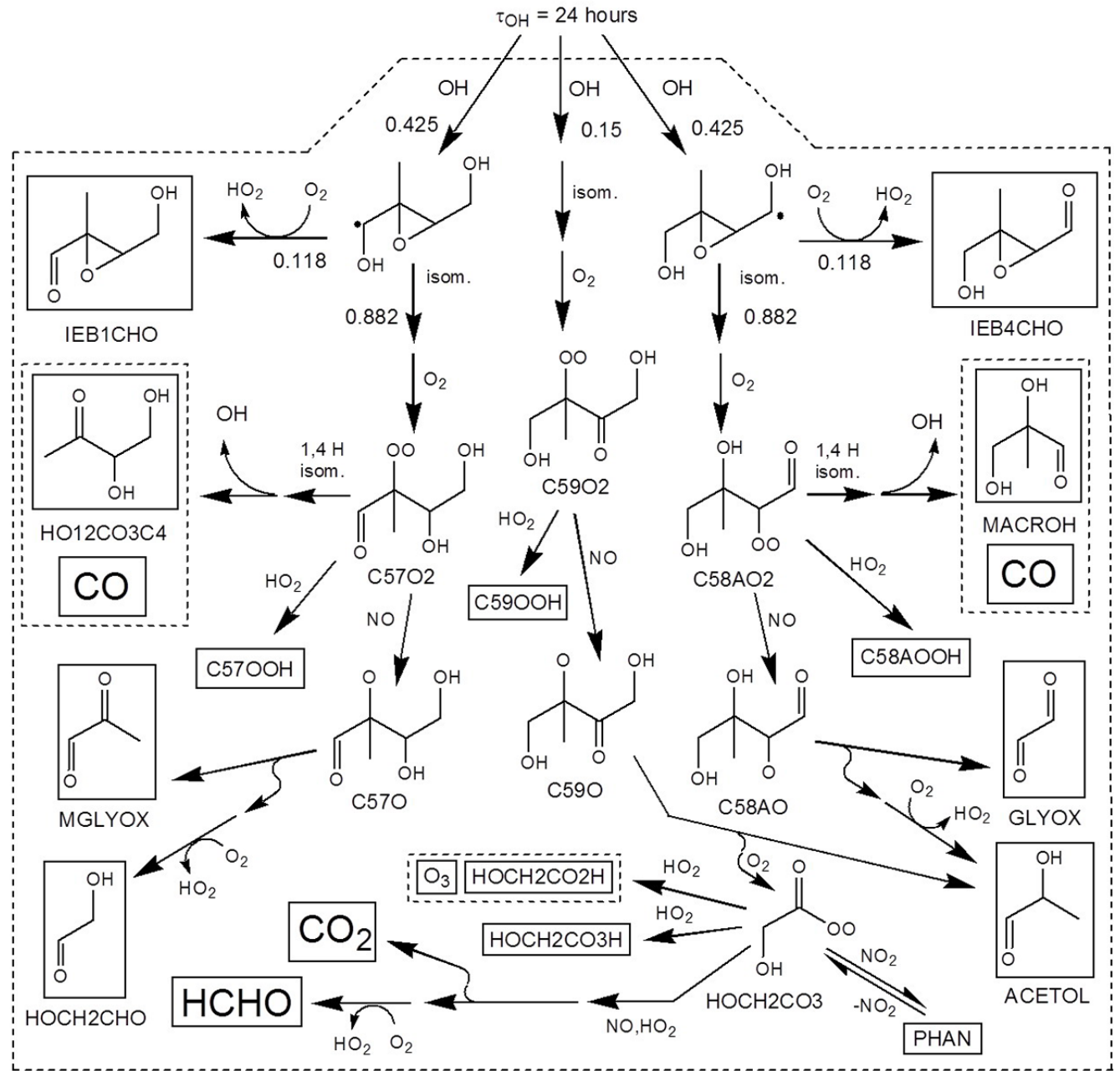

Figure 8. Overview of the OH-initiated degradation of isoprene hydroxy-hydroperoxides, as represented in MCM v3.3.1. The dominant formation of the isomeric epoxydiol products is shown, with the further degradation of the most abundant isomer, IEPOXB. For clarity, the terminating reactions of peroxy radicals with $\mathrm{NO}$ and the reactions of peroxy radicals with $\mathrm{NO}_{3}$ and the peroxy pool are not shown. Representative lifetimes $\left(\tau_{\mathrm{OH}}\right)$ for reactions with $\mathrm{OH}$ are shown, based on $[\mathrm{OH}]=10^{6}$ molecule cm $^{-3}$. 
sequential formation and removal kinetics of the hydroperoxide and epoxydiol isomers reported by Paulot et al. (2009a). However, there is clearly some uncertainty in the lifetimes of these species.

The main features of the subsequent degradation chemistry of IEPOXB are shown in Fig. 8. These are also largely based on the mechanism presented by Bates et al. (2014), which can potentially account for the formation of a number of end products reported and quantified in that study. The mechanism thus produces a low yield $(11 \%)$ of products retaining the epoxide group (i.e. IEB1CHO and IEB4CHO). The remainder of the chemistry forms three ring-opened isomeric peroxy radicals, C57O2 (37\%), C58AO2 (37\%) and $\mathrm{C} 59 \mathrm{O} 2(15 \%)$, which all also have a number of other sources in the MCM v3.3.1 isoprene chemistry. As indicated above in Sects. 2.1.4 and 2.2.1, the more abundant $\alpha$-formyl peroxy radical isomers (C57O2 and C58AO2) are also generated from the degradation of the $\mathrm{C}_{5}$ hydroxy carbonyls (HC4ACHO and $\mathrm{HC} 4 \mathrm{CCHO}$ ). The newly implemented $1,4 \mathrm{H}$ atom shift isomerisation reactions are likely to be the dominant fates for $\mathrm{C} 57 \mathrm{O} 2$ and $\mathrm{C} 58 \mathrm{AO} 2$ under most atmospheric conditions (see Sect. 2.2.1), leading to the formation of $\mathrm{OH}, \mathrm{CO}$ and the dihydroxycarbonyl products, MACROH and $\mathrm{HO} 12 \mathrm{CO} 3 \mathrm{C} 4$ (see Fig. 8). The significant formation of these species is also consistent with the product study of Bates et al. (2014).

\subsubsection{Unsaturated $C_{5}$ hydroperoxyaldehydes (HPALDs)}

Figure 9 shows the main features of the degradation chemistry for the newly implemented unsaturated $\mathrm{C}_{5}$ hydroperoxyaldehydes, C5HPALD1 and C5HPALD2, which is based on information provided in the appraisals of Peeters and co-workers (Peeters et al., 2009, 2014; Peeters and Müller, 2010).

The dominant fate of the hydroperoxyaldehydes is photolysis, which results from absorption into the $\alpha, \beta$-enal chromophore, followed by dissociation of the weak $\mathrm{O}-\mathrm{O}$ bond in the hydroperoxide group, to form $\mathrm{OH}$ and an energy-rich $\mathrm{C}_{5}$ oxy radical in each case (see Fig. 9). Efficient photolysis was originally proposed by Peeters et al. (2009), with subsequent experimental confirmation reported by Wolfe et al. (2012) for the structurally similar species, $E$-4-hydroxyperoxy-hex-2enal. The assigned photolysis rate is thus based on the UV absorption cross sections of the well-studied $\alpha, \beta$-enal, MACR, with an assumed unity quantum yield, leading to an associated clear sky lifetime of about $30 \mathrm{~min}$ (for solar zenith angle $=30^{\circ}$ ). As discussed by Peeters et al. (2014), the subsequent chemistry of the $\mathrm{C}_{5}$ oxy radical products is subject to some uncertainty, but is provisionally based on information provided in that study for the $Z$ conformer of C5HPALD1, supplemented by rules as defined in the previous MCM protocol (Saunders et al., 2003). This leads to the formation of two new unsaturated $\mathrm{C}_{4}$ hydroxycarbonyl products (HVMK and HMAC in Fig. 9).

As shown in Fig. 9, the reactions of OH with C5HPALD1 and C5HPALD2 are also represented, with these reactions typically making a minor contribution to the removal of the hydroperoxyaldehydes. The rate coefficients and product channels for these reactions are based on the appraisal of Peeters and Müller (2010), leading to associated atmospheric lifetimes of about $5 \mathrm{~h}$ (for $[\mathrm{OH}]=10^{6}$ molecule $\mathrm{cm}^{-3}$ ). The reactions of the hydroperoxyaldehyde species with $\mathrm{O}_{3}$ and $\mathrm{NO}_{3}$ are also included in MCM v3.3.1, with representations that are consistent with the rules in the MCM protocol (Saunders et al., 2003).

\subsubsection{Glyoxal}

The chemistry of the HCOCO radical, formed most significantly from the $\mathrm{OH}$-initiated oxidation of glyoxal (GLYOX), has been updated in MCM v3.3.1. This has taken particular account of information reported in the studies of Orlando and Tyndall (2001), da Silva (2010) and Lockhart et al. (2013). As a result, the mechanism now includes a temperature and $\left[\mathrm{O}_{2}\right]$ dependence for the relative formation of $\mathrm{CO}$ and $\mathrm{CO}_{2}$, a route to direct $\mathrm{OH}$ recycling and no longer sequesters $\mathrm{NO}_{x}$ in the form of the PAN (peroxyacetyl nitrate) species, $\mathrm{HC}(\mathrm{O}) \mathrm{C}(\mathrm{O}) \mathrm{O}_{2} \mathrm{NO}_{2}$ (see Sect. $\mathrm{S} 2.1$ for further details).

\subsubsection{3-methylfuran}

The rate coefficient for the reaction of $\mathrm{OH}$ with 3methylfuran is based on the studies of Atkinson et al. (1989) and Aschmann et al. (2011), leading to an associated atmospheric lifetime of about $3 \mathrm{~h}$ (for $[\mathrm{OH}]$ $=10^{6}$ molecule $\mathrm{cm}^{-3}$ ). The subsequent mechanism currently leads to quantitative formation of $\mathrm{HO}_{2}$ and 2methylbutenedial (C4MDIAL), which is consistent with the yield of $(83 \pm 33) \%$ reported by Gómez Gómez Alvarez et al. (2009), and informed by the theoretical study of Zhang et al. (2008). However, it is noted that Aschmann et al. (2014) have recently reported a lower yield of $(38 \pm 2) \%$ from experiments with much higher levels of NO (about $5 \mathrm{ppm}$ ), indicating that the mechanism is probably [NO] dependent. The chemistry initiated by the reactions with $\mathrm{O}_{3}$ and $\mathrm{NO}_{3}$ is also represented, with the rate coefficients taken from the study of Alvarado et al. (1996) and subsequent mechanisms based on rules presented previously (Saunders et al., 2003).

\subsubsection{Other products}

The updates to the chemistry described above lead to the formation of a number of other new products. These include the unsaturated $\mathrm{C}_{5}$ carbonyls (PE4E2CO and ME3BU3ECHO) (Fig. 1), the unsaturated $\mathrm{C}_{4}$ hydroxycarbonyls (HVMK and HMAC) (Fig. 9), the $\mathrm{C}_{4}$ dihydroperoxycarbonyls (DHPMEK and DHPMPAL) (Fig. 3), HMML (Fig. 6), MAE (Fig. 6), 


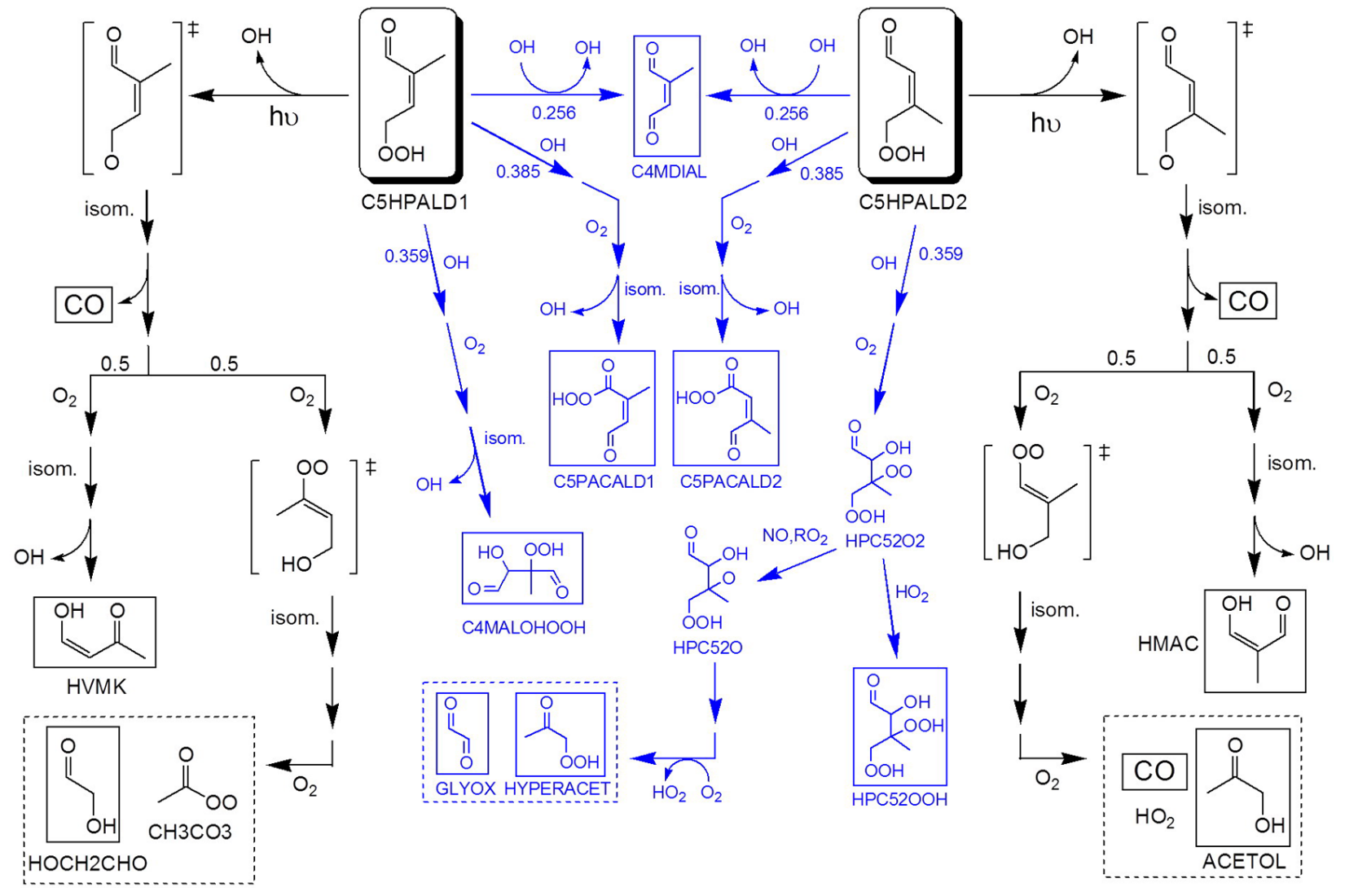

Figure 9. Overview of the degradation mechanisms for the unsaturated $\mathrm{C}_{5}$ hydroperoxyaldehydes, C5HPALD1 and C5HPALD2, as currently represented in MCM v3.3.1. The (major) chemistry initiated by photolysis is shown in black, and the (minor) OH-initiated chemistry is shown in blue. For clarity, the reactions of the peroxy radicals with $\mathrm{NO}_{3}$ are not shown.

and other (usually minor) multifunctional products containing combinations of functional groups. These compounds are all degraded using the rules presented previously by Jenkin et al. (1997) and Saunders et al. (2003). The degradation chemistry of HMML is augmented to take account of chemistry reported more recently for the epoxydiol, IEPOXB (Bates et al., 2014), and results in partial formation of $\mathrm{HCOOH}$ (see Sect. S2.2 for further details).

In the cases of HVMK and HMAC, removal via rapid photolysis (initially forming $\mathrm{OH}$ and a stabilised hydroxyvinyl radical) is also represented, as recommended by Peeters et al. (2014) and in the discussion comment of Müller (2015). This leads to clear sky photolysis lifetimes of about $1 \mathrm{~h}$ for HVMK and HMAC (for solar zenith angle $=30^{\circ}$ ).

\subsection{Generic updates}

Small revisions were made to a number of generic rate coefficients for peroxy radical reactions in MCM v3.2, and these are retained in $\mathrm{MCM} \vee 3.3 .1$. These include those for the reactions of acyl peroxy radicals (of generic formula $\mathrm{RC}(\mathrm{O}) \mathrm{O}_{2}$ ) with $\mathrm{NO}$ and $\mathrm{HO}_{2}$, and the reference rate coefficient for the reactions of other peroxy radicals with $\mathrm{NO}$ and $\mathrm{NO}_{3}$ (see Sect. S2 and Table S3 for further details).

The reactions of acyl peroxy radicals with $\mathrm{HO}_{2}$ were also previously revised to include major radical propagating channels as follows:

$\mathrm{RC}(\mathrm{O}) \mathrm{O}_{2}+\mathrm{HO}_{2} \rightarrow \mathrm{RC}(\mathrm{O}) \mathrm{O}+\mathrm{OH}+\mathrm{O}_{2}$.

This has relevance to the reactions of 47 complex acyl peroxy radicals formed during isoprene degradation in MCM v3.3.1 (e.g. the methacryloyl peroxy radical, MACO3, formed from methacrolein), in addition to $\mathrm{CH}_{3} \mathrm{C}(\mathrm{O}) \mathrm{O}_{2}$ itself. The branching ratios are based on the current IUPAC recommendations for the reaction of $\mathrm{CH}_{3} \mathrm{C}(\mathrm{O}) \mathrm{O}_{2}$ with $\mathrm{HO}_{2}$ (http://iupac.pole-ether.fr/), such that $44 \%$ of the reaction proceeds via the propagating channel (Reaction R1) in each case; this being based on the experimental determinations of Hasson et al. (2004), Jenkin et al. (2007) and Dillon and Crowley (2008). It is noted that the recent results of Groß et al. (2014), based on direct $\mathrm{OH}$ detection, suggest an even higher branching ratio, $(62 \pm 9) \%$, and this may therefore influence future recommendations.

The rate coefficients for the formation and back decomposition of $\mathrm{PAN}\left(\mathrm{CH}_{3} \mathrm{C}(\mathrm{O}) \mathrm{OONO}_{2}\right)$ have been updated in 
MCM v3.3.1, on the basis of the recent recommendations of the IUPAC Task Group (http://iupac.pole-ether.fr/). These rate coefficients are also applied to the analogous reactions forming and removing peroxyacyl nitrates in general, with the exception of MPAN decomposition, for which the rate coefficient remains based on the IUPAC recommendation for that specific reaction.

\section{Examination of the performance of MCM v3.3.1}

The performance of the MCM v3.3.1 isoprene mechanism was compared with those of MCM v3.1 and MCM v3.2 using simulations carried out with a boundary layer box model, coded for application with the FACSIMILE kinetics integration package (MCPA Software). The aim of these studies was to examine and illustrate the effects of the updates described in Sect. 2 for a range of idealised atmospheric conditions, with particular emphasis on the impacts on $\mathrm{HO}_{x}$ and $\mathrm{NO}_{x}$ partitioning and recycling.

\subsection{Model description}

The model was designed to simulate a well-mixed tropical forested boundary layer, $1000 \mathrm{~m}$ in depth. The boundary layer air parcel was continuously exchanged with the free troposphere on a timescale of 1 day, thus representing a loss process for longer-lived products. The free troposphere was assumed to contain the following limited series of trace species, which were mixed into the boundary layer on the same timescale: $\mathrm{O}_{3}(20 \mathrm{ppb}), \mathrm{CO}(100 \mathrm{ppb})$, and $\mathrm{HCHO}$ (300 ppt). The model was initialised for 7 days such that exchange processes reached steady state, and results from the daylight portion of the eighth diurnal cycle were used in comparisons of mechanism performance. The temperature followed a sinusoidal diurnal profile (average $298 \mathrm{~K}$; amplitude $4 \mathrm{~K}$ ), leading to a peak temperature of $302 \mathrm{~K}$ in the early afternoon. The diurnal variation of photolysis parameters was set for a latitude of $0^{\circ}$ at equinox in all simulations. Photolysis coefficients were calculated assuming clear sky conditions, using a parameterization previously applied with the MCM (Saunders et al., 2003). For the present illustration, the loss of product species via deposition or transfer to the condensed phase was not represented, the focus of the simulations being chemical processing in the gas phase. The same inorganic reaction scheme and parameters were used with each MCM version, so that the differences in performance result from the changes to the organic chemistry, as summarised above.

The boundary layer box received continuous emissions of isoprene and $\mathrm{NO}_{x}$, which were maintained throughout the model runs, and a fixed mixing ratio of $1.8 \mathrm{ppm}$ methane was assumed. A base $\mathrm{NO}_{x}$ emission rate of $4.7 \times 10^{9}$ molecule $\mathrm{cm}^{-2} \mathrm{~s}^{-1}$ was applied, which is a globally averaged rate based on an annual total emission of
44.8 TgN, as applied by Derwent et al. (2003). This resulted in daylight-averaged $\mathrm{NO}_{x}$ mixing ratios of about $30 \mathrm{ppt}$ (with small variations between mechanisms). To examine the $\mathrm{NO}_{x}$ dependence of the chemistry, the $\mathrm{NO}_{x}$ emission rate was scaled by factors of 3, 10, 30, 100 and 200 which resulted in daylight-averaged $\mathrm{NO}_{x}$ mixing ratios up to about $8 \mathrm{ppb}$ (again with small variations between mechanisms). The relative isoprene emission rate varied with temperature and photosynthetically active radiation (PAR) throughout the diurnal cycle, based on a standard algorithm (Guenther et al., 1995). The absolute magnitude of the emissions was set such that the daylight average emission rate was $7.6 \times 10^{11}$ molecule $\mathrm{cm}^{-2} \mathrm{~s}^{-1}\left(3.1 \mathrm{mg} \mathrm{m}^{-2} \mathrm{~h}^{-1}\right)$, maximising at $1.0 \times 10^{12}$ molecule $\mathrm{cm}^{-2} \mathrm{~s}^{-1}\left(4.2 \mathrm{mg} \mathrm{m}^{-2} \mathrm{~h}^{-1}\right)$ in the early afternoon. These emissions fluxes are typical of those reported for tropical forested regions (e.g. Eerdekens et al., 2009).

Reaction with $\mathrm{OH}$ was the dominant fate of isoprene for the conditions of this illustration, accounting for between 89 and $93 \%$ of isoprene removal in the MCM v3.3.1 simulations (depending on the $\mathrm{NO}_{x}$ level). The contribution of the $\mathrm{O}_{3}$-initiated chemistry increases from about $4 \%$ at the high end of the $\mathrm{NO}_{x}$ range to about $11 \%$ at the low end of the $\mathrm{NO}_{x}$ range. The $\mathrm{NO}_{3}$-initiated chemistry is also simulated to contribute up to about $4 \%$ to isoprene removal, with the maximum contribution towards the high end of the $\mathrm{NO}_{x}$ range.

\subsection{Results}

Selected results of the series of simulations using the MCM v3.3.1 isoprene chemistry are shown in Figs. 10-15, along with the corresponding results of simulations using MCM v3.1 and MCM v3.2, where applicable. These illustrate the simulated daytime-averaged levels of a number of key species formed during isoprene degradation, or fluxes through key reactions, and their dependence on the level of $\mathrm{NO}_{x}$.

\subsubsection{Ozone}

As shown in Fig. 10, the simulated levels of $\mathrm{O}_{3}$ are relatively insensitive to the mechanistic updates implemented in MCM v3.2 and MCM v3.3.1. Consistent with conventional understanding of VOC degradation (e.g. Jenkin and Clemitshaw, 2000), the simulated formation of $\mathrm{O}_{3}$ with all the mechanisms progressively increases with the availability of $\mathrm{NO}_{x}$, leading to maximum mixing ratios of between 86 and $91 \mathrm{ppb}$ close to the high end of the range of $\mathrm{NO}_{x}$ inputs considered (see Fig. 10), corresponding to average $\mathrm{O}_{3}$ production rates of almost $3 \mathrm{ppb} \mathrm{h}^{-1}$. At the low end of the $\mathrm{NO}_{x}$ input range, the chemistry leads to very slight net $\mathrm{O}_{3}$ removal, at rates between -0.02 and $-0.07 \mathrm{ppb} \mathrm{h}^{-1}$. This is because its removal via direct photolysis and reaction with isoprene, and its reactions with $\mathrm{HO}_{2}$ and $\mathrm{OH}$, slightly outweigh its formation from the $\mathrm{NO}_{x}$-catalysed free radical chemistry and other mi- 

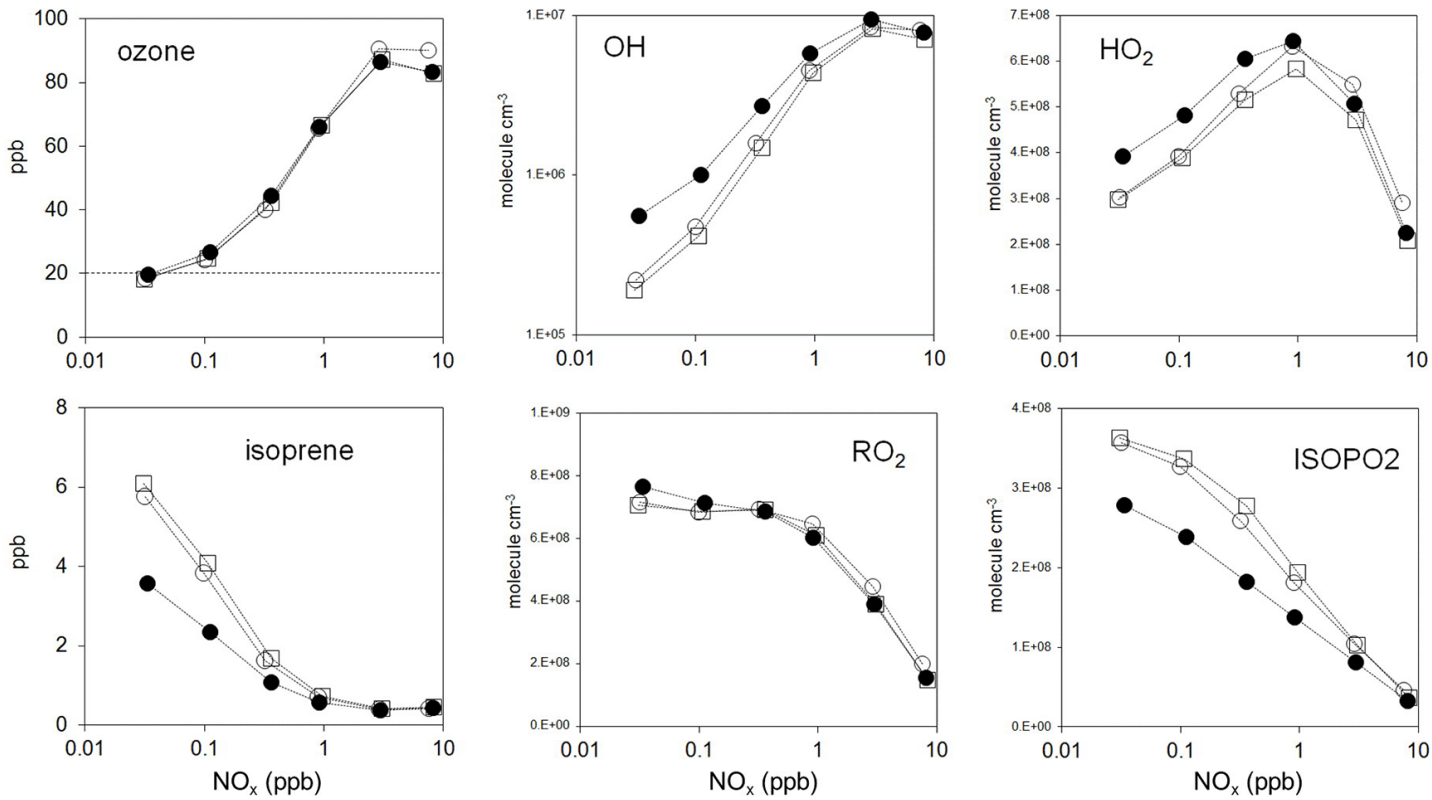

$\because \mathrm{MCM}$ v3.1 $\odot \mathrm{MCM}$ v3.2 $\quad$ - MCM v3.3.1

Figure 10. Comparison of performances of MCM v3.1, MCM v3.2 and MCM v3.3.1, showing the $\mathrm{NO}_{x}$ dependence of the daylight-averaged mixing ratios or concentrations of $\mathrm{O}_{3}$, isoprene, $\mathrm{OH}, \mathrm{HO}_{2}$, total organic peroxy radicals $\left(\mathrm{RO}_{2}\right)$ and peroxy radicals formed from the firstgeneration $\mathrm{OH}$-initiated chemistry (ISOPO2). The broken line in the $\mathrm{O}_{3}$ panel shows the background mixing ratio relative to which $\mathrm{O}_{3}$ is either produced or destroyed (see text).

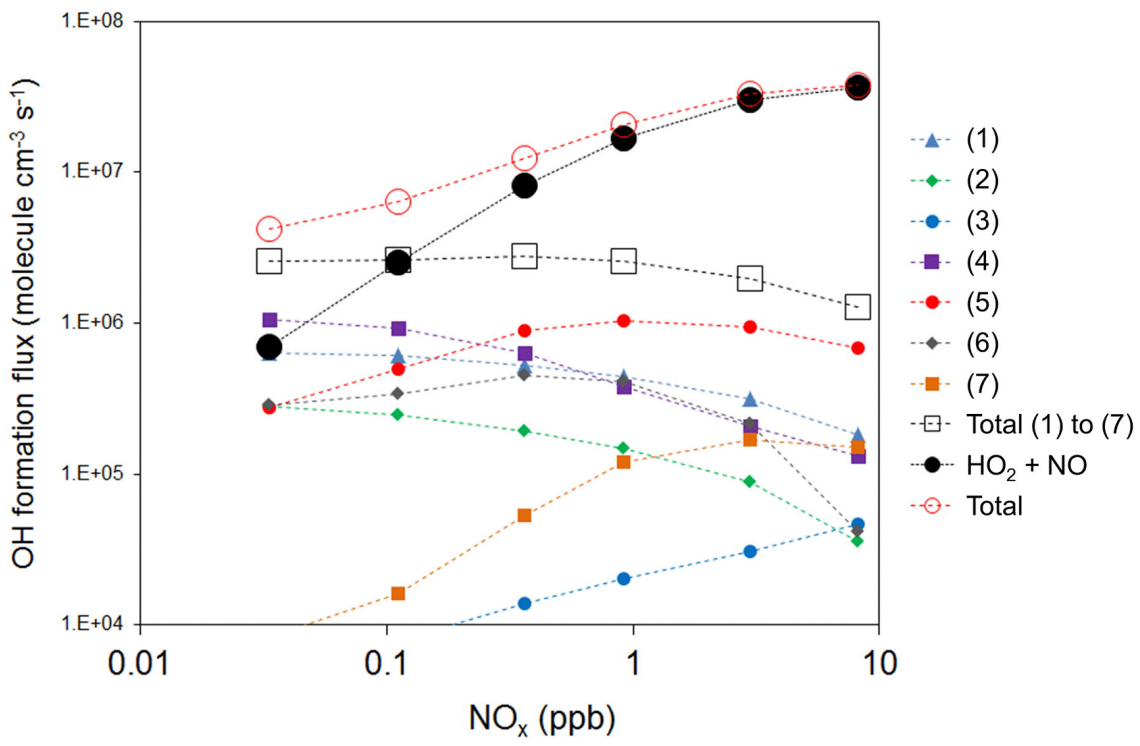

Figure 11. Comparison of daylight-averaged fluxes through the newly implemented $\mathrm{OH}$ regeneration routes with that through the reaction of $\mathrm{HO}_{2}$ with NO. (1) First-generation chemistry of C536O2 and C537O2 (Fig. 3), dominated by their 1,4 H shift reactions; (2) first-generation $1,5 \mathrm{H}$ shift reactions (i.e from ISOPBO2, ISOPDO2 or C524O2) (Figs. 2, S3); (3) first-generation chemistry of C526O2 and C527O2 (Figs. S1, S2), dominated by their 1,4 H shift reactions; (4) reaction sequence following the rapid photolysis of C5HPALD1 and C5HPALD2 (Fig. 9), including subsequent rapid photolysis of HMAC and HVMK (Sect. 2.2.7); (5) higher-generation 1,4 H shift isomerisation reactions (e.g. from MACRO2, $\mathrm{C} 57 \mathrm{O} 2$ and C58AO2) (Figs. 6, 8); (6) $\mathrm{RC}(\mathrm{O}) \mathrm{O}_{2}+\mathrm{HO}_{2}$ reactions (Sect. 2.3); and (7) $\mathrm{HCOCO}+\mathrm{O}_{2}($ i.e. included in the update to glyoxal chemistry, Sect 2.2.5). 

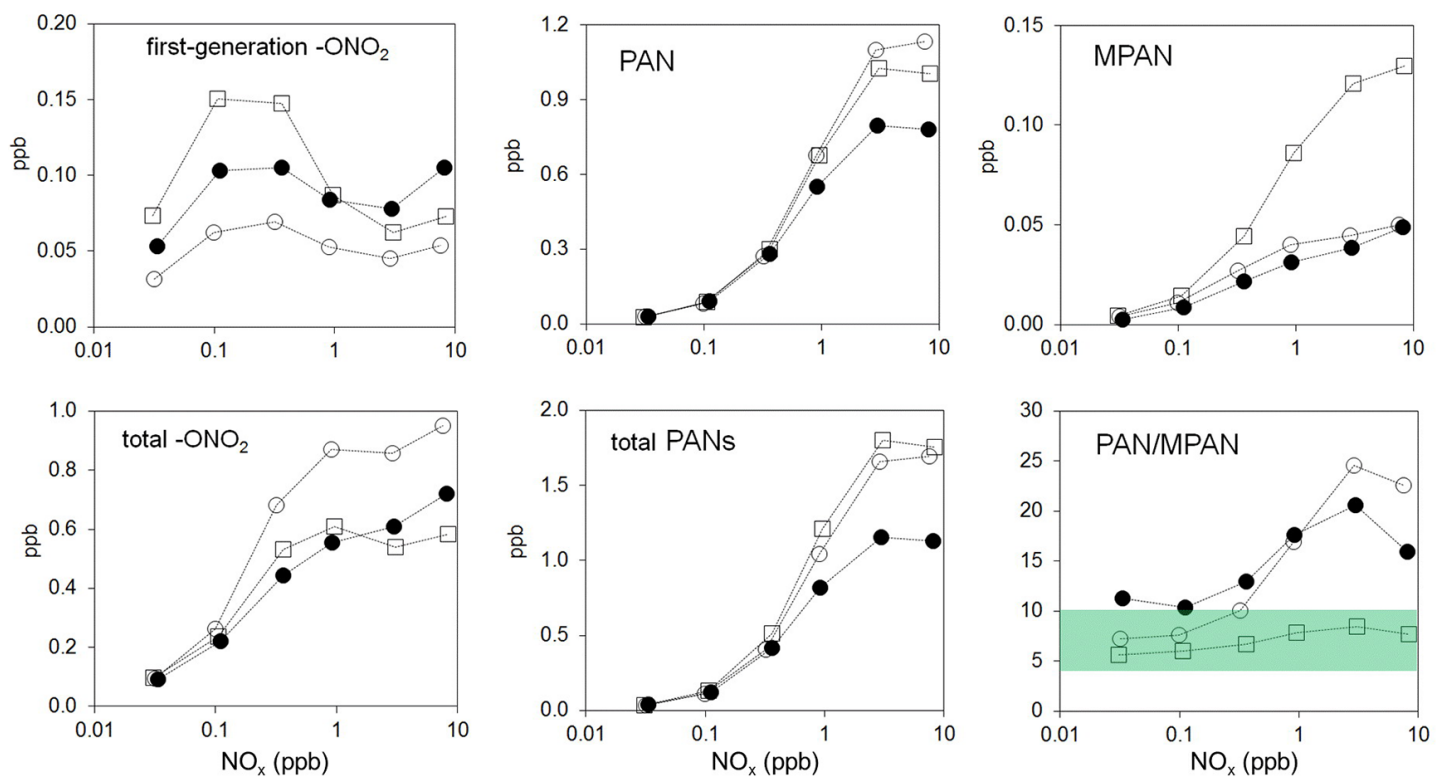

$\because \mathrm{MCM}$ v3.1 $\odot \mathrm{MCM}$ v3.2

MCM v3.3.1

Figure 12. Comparison of the performances of MCM v3.1, MCM v3.2 and MCM v3.3.1, showing the $\mathrm{NO}_{x}$ dependence of the daylightaveraged mixing ratios of the organic oxidised nitrogen reservoirs, nitrates $\left(-\mathrm{ONO}_{2}\right)$ and PANs, and the daylight-averaged PAN / MPAN ratio. The first-generation nitrates are specifically those formed from the reactions of NO with first-generation peroxy radicals (denoted "ISOPO2" in Fig. 10). The shaded band in the PAN / MPAN panel represents the typical range of reported observed values in isoprenedominated environments (see text).

nor sources (i.e. the minor channels of the reactions of $\mathrm{HO}_{2}$ with acyl peroxy radicals).

\subsection{2 $\mathrm{HO}_{\mathrm{x}}$ radicals}

Figure 10 also shows the impact of varying the $\mathrm{NO}_{x}$ input on the simulated concentrations of $\mathrm{HO}_{x}$ radicals. This shows the well-documented suppression of calculated $\mathrm{OH}$ concentrations as the $\mathrm{NO}_{x}$ levels decrease (e.g. Jenkin et al., 1993; Lelieveld et al., 2008), which results from the progressively decreasing efficiency of $\mathrm{OH}$ regeneration from the $\mathrm{NO}_{x}$-catalysed free radical chemistry. This is particularly pronounced in the MCM v3.1 results, with the concentration of $\mathrm{OH}$ varying from a maximum of about $8 \times 10^{6}$ molecule $\mathrm{cm}^{-3}$ close to the high end of the $\mathrm{NO}_{x}$ range to below $2 \times 10^{5}$ molecule $\mathrm{cm}^{-3}$ at the low end of the range. As described above in Sect. 2, the updates implemented in MCM v3.2 and MCM v3.3.1 are expected to have a collectively significant impact on $\mathrm{OH}$ radical regeneration at lower $\mathrm{NO}_{x}$ levels. This is clearly apparent in the MCM v3.3.1 results presented in Fig. 10, for which the $\mathrm{OH}$ concentrations are a factor of 3 greater at the low end of the $\mathrm{NO}_{x}$ range than those simulated with MCM v3.1, with this also suppressing the simulated isoprene mixing ratio. To illustrate this further, Fig. 11 compares the fluxes through the newly implemented $\mathrm{OH}$ regeneration routes with that through the reaction of $\mathrm{HO}_{2}$ with $\mathrm{NO}$ (i.e. that resulting from the $\mathrm{NO}_{x}$ catalysed free radical chemistry). This confirms that the collective flux through the new routes makes a notable contribution at sub-ppb $\mathrm{NO}_{x}$ levels and exceeds that from the $\mathrm{NO}_{x}-$ catalysed free radical chemistry at $\mathrm{NO}_{x}$ levels below $100 \mathrm{ppt}$. Particularly important contributions are simulated to result from the chemistry initiated by the 1,6 $\mathrm{H}$ atom shift isomerisation reactions of CISOPAO2 and $\mathrm{CISOPCO} 2$ (including the $1,4 \mathrm{H}$ shift reactions of $\mathrm{C} 536 \mathrm{O} 2$ and $\mathrm{C} 537 \mathrm{O} 2$ and the photolysis of C5HPALD1 and C5HPALD2; see Sects. 2.1.2 and 2.2.4) and from the higher-generation $1,4 \mathrm{H}$ atom shift isomerisation reactions for MACRO2, $\mathrm{C} 57 \mathrm{O} 2$ and $\mathrm{C} 58 \mathrm{AO} 2$ (see Sect. 2.2.1).

The newly implemented updates also lead to (more modest) increases in the $\mathrm{HO}_{2}$ radical concentrations, with those simulated with MCM v3.3.1 being about $30 \%$ greater at the low end of the $\mathrm{NO}_{x}$ range than those simulated with MCM v3.1 (see Fig. 10). The simulated total concentration of organic peroxy radicals $\left(\mathrm{RO}_{2}\right)$ is insensitive to the mechanistic changes, although the first-generation peroxy radicals (denoted "ISOPO2" in Fig. 10) make a reduced contribution to the total in the MCM v3.3.1 simulation, particularly at lower $\mathrm{NO}_{x}$ levels. This results mainly from the significant operation of the newly implemented peroxy radical isomerisation reactions in MCM v3.3.1. 
(a) Fractional contribution of initiation reactions
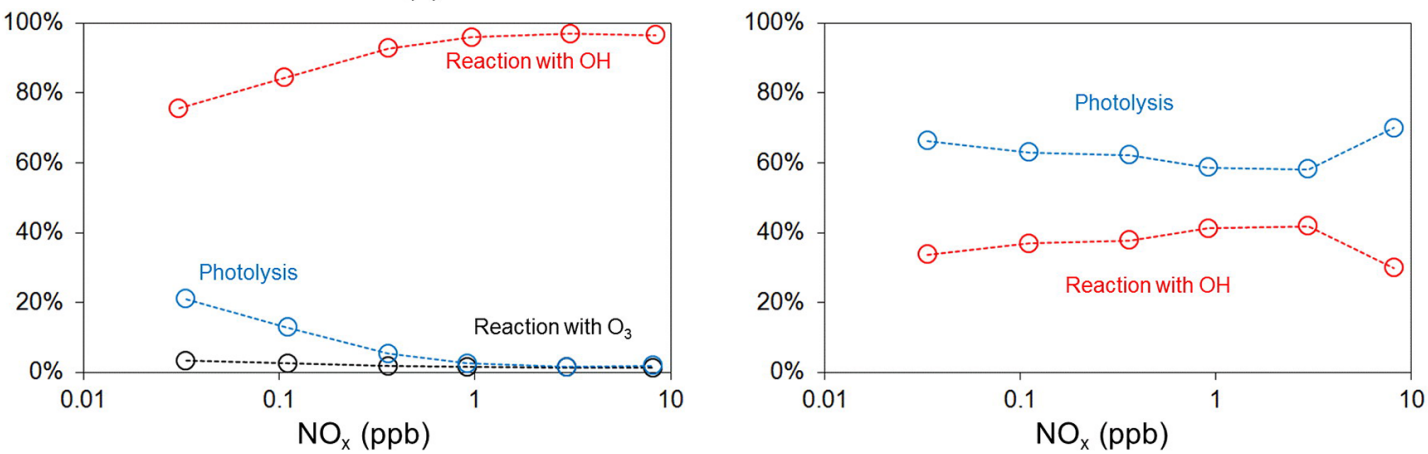

(b) Fractional $\mathrm{NO}_{x}$ regeneration
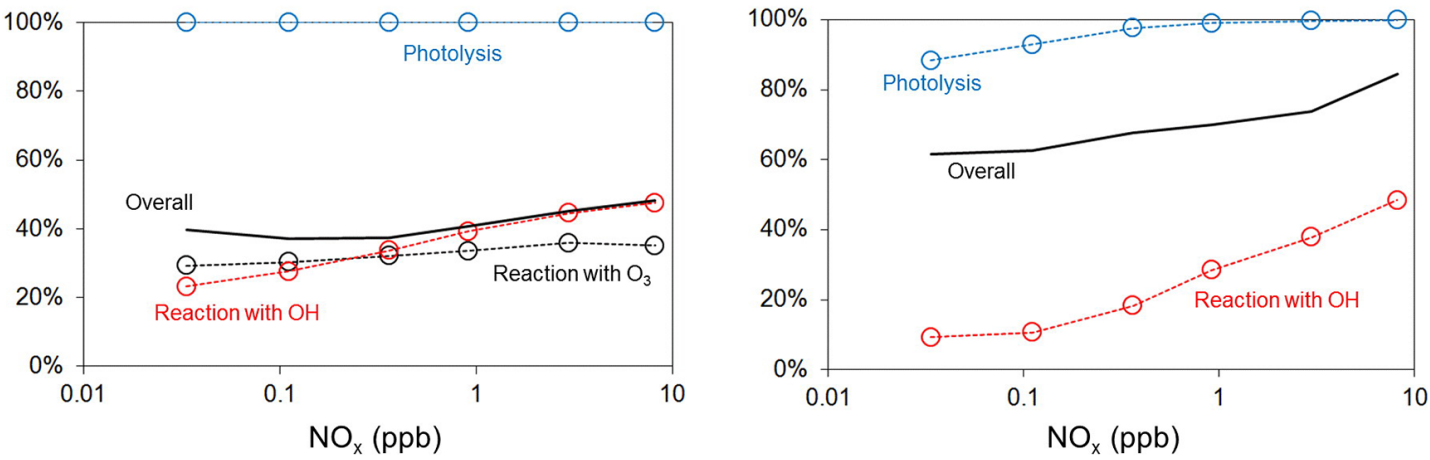

Figure 13. (a) Comparison of the fractional contributions of the initiation reactions contributing to the removal of first- and second-generation organic nitrates in the MCM v3.3.1 simulations. (b) The fractional regeneration of $\mathrm{NO}_{x}$ resulting from each of the initiation reactions for first- and second-generation organic nitrates and the overall fractional $\mathrm{NO}_{x}$ regeneration in each case.

\subsubsection{Oxidised organic nitrogen}

Figure 12 shows the simulated levels of organic nitrates (i.e. species containing $-\mathrm{ONO}_{2}$ groups) and PANs (i.e. species containing $-\mathrm{C}(\mathrm{O}) \mathrm{OONO}_{2}$ groups), and subsets of these totals. The results for the organic nitrates show that the updates implemented in MCM v3.2 and MCM v3.3.1 have a considerable impact on the simulated abundance of those formed from the first-generation $\mathrm{OH}$-initiated chemistry (denoted "first-generation $-\mathrm{ONO}_{2}$ " in Fig. 12). The suppression in the simulated levels in MCM v3.2 relative to MCM v3.1 results mainly from the inclusion of the $\mathrm{O}_{3}$-initiated removal chemistry. As discussed in Sect. 2.2.2, revisions to the rate coefficients for the $\mathrm{O}_{3}$ reactions in MCM v3.3.1 result in a notable reduction in the importance of the $\mathrm{O}_{3}$-initiated chemistry compared with MCM v3.2, leading to an increase in the abundance of the first-generation nitrates. The distribution of first-generation nitrates also has a reduced $\mathrm{OH}$ reactivity in MCM v3.3.1, resulting from both the changes to the nitrateforming branching ratios for the $\beta$-hydroxy peroxy radicals (Sect. 2.1.2) and from the reduction in the fractional contribution of the more reactive $\delta$-hydroxy species (ISOPANO3 and ISOPDNO3) under atmospheric conditions (see Fig. 5b).
Despite this, the first-generation nitrate levels at low $\mathrm{NO}_{x}$ remain substantially suppressed relative to the MCM v3.1 simulation. This is partly because of the greater abundance of $\mathrm{OH}$ radicals, leading to enhanced removal rates, and partly because the significant operation of the newly implemented peroxy radical isomerisation reactions in MCM v3.3.1 reduces the yield of first-generation nitrates at lower $\mathrm{NO}_{x}$ levels.

The simulated abundance of total organic nitrates also shows differences that result from the substantial updates made to the chemistry in MCM v3.2 and MCM v3.3.1 (see Sect. 2.2.2). The more rigorous representation of the formation of higher-generation nitrates in MCM v3.2 leads to a notable increase in the total organic nitrate abundance. However, the levels simulated with MCM v3.3.1 are reduced relative those with MCM v3.2. This is mainly because of the implementation of rapid photolysis for $\alpha$ - and $\beta$-carbonyl nitrates (which make a large contribution to the higher-generation species) leading to $\mathrm{NO}_{x}$ regeneration and also because of the greater abundance of $\mathrm{OH}$ radicals at low $\mathrm{NO}_{x}$. 

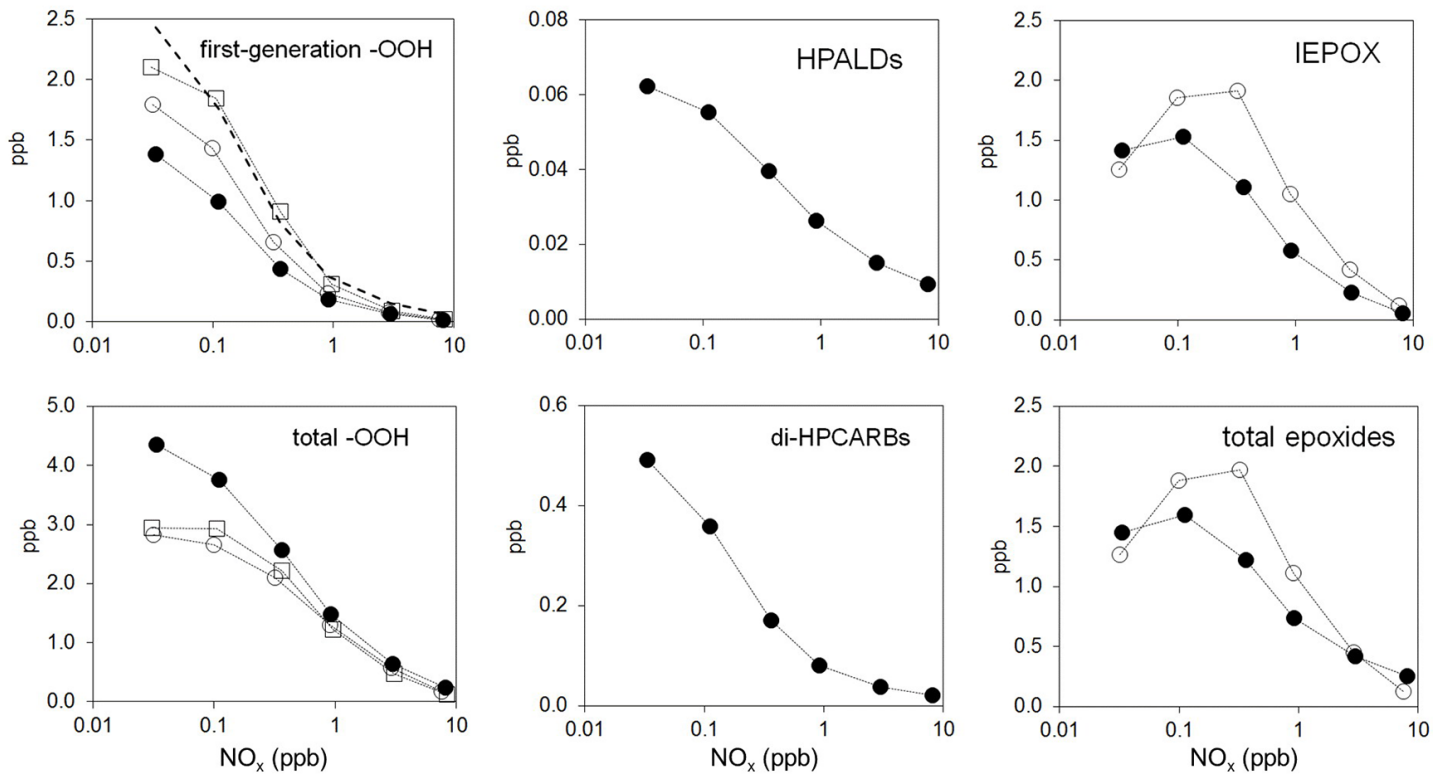

MCM v3.1 $\odot$ MCM v3.2 $\bullet$ MCM v3.3.1

Figure 14. Comparison of the performances of MCM v3.1, MCM v3.2 and MCM v3.3.1, showing the $\mathrm{NO}_{x}$ dependence of the daylightaveraged mixing ratios of selected hydroperoxides and epoxides. The first-generation hydroperoxides are specifically those formed from the reactions of $\mathrm{HO}_{2}$ with first-generation peroxy radicals (denoted "ISOPO2" in Fig. 10). HPALDs are C5HPALD1 and C5HPALD2; diHPCARBs are DHPMEK and DHPMPAL; and IEPOX includes the epoxydiols, IEPOXA, IEPOXB and IEPOXC. The heavy broken line in the "first-generation-OOH" panel shows the effect of including HPALDs and di-HPCARBs in the MCM v3.3.1 total.

To illustrate the details of the nitrate chemistry further, Fig. 13 shows the relative contributions of the initiation reactions contributing to the removal of first- and secondgeneration organic nitrates in the MCM v3.3.1 simulations and the associated regeneration of $\mathrm{NO}_{x}$. The oxidation of the first-generation nitrates is mainly initiated by reaction with $\mathrm{OH}$, accounting for between 76 and $97 \%$ of the removal depending on the level of $\mathrm{NO}_{x}$. At the high end of the $\mathrm{NO}_{x}$ range, the $\mathrm{OH}$-initiated oxidation results in $47 \%$ regeneration of $\mathrm{NO}_{x}$ (along with $43 \%$ formation of mononitrate products and $10 \%$ formation of dinitrate products), consistent with the appraisal in Sect. 2.2.2 and Fig. 7. As shown in Fig. 13, the extent of $\mathrm{NO}_{x}$ regeneration from the $\mathrm{OH}-$ initiated chemistry progressively decreases with the level of $\mathrm{NO}_{x}$, to just over $20 \%$ at the low end of the $\mathrm{NO}_{x}$ range. This is because of the increasing operation of termination reactions for the intermediate nitro-oxy peroxy radicals, and the associated formation of nitrate-retaining products (e.g. hydroperoxynitrates from the termination reactions with $\mathrm{HO}_{2}$ ). However, the increasing contribution of photolysis to firstgeneration nitrate removal at low $\mathrm{NO}_{x}$ levels (with associated quantitative $\mathrm{NO}_{x}$ formation) supplements $\mathrm{NO}_{x}$ regeneration, such that the total extent of $\mathrm{NO}_{x}$ regeneration from the first-generation nitrates is close to $40 \%$ for most of the $\mathrm{NO}_{x}$ range, for the conditions of the present simulations.
As also shown in Fig. 13, the oxidation of the secondgeneration nitrates is initiated significantly by both photolysis and reaction with $\mathrm{OH}$, with photolysis generally making the major contribution (60-70\%). As indicated above, this is mainly because of the implementation of rapid photolysis for $\alpha$ - and $\beta$-carbonyl nitrates, which make a large contribution to the second-generation species. At the high end of the $\mathrm{NO}_{x}$ range, these species dominate the distribution, with their photolysis resulting in essentially quantitative $\mathrm{NO}_{x}$ formation (see Sect. 2.2.2). The increasing contribution of other nitrate species at lower $\mathrm{NO}_{x}$ (e.g. hydroperoxynitrates) leads to a decrease of the associated $\mathrm{NO}_{x}$ regeneration to just below $90 \%$ at the low end of the range. The $\mathrm{OH}$-initiated oxidation results in about $50 \% \mathrm{NO}_{x}$ regeneration at the high end of the $\mathrm{NO}_{x}$ range (consistent with the appraisal in Sect. 2.2.2 and Fig. 7), although with this steadily decreasing with $\mathrm{NO}_{x}$ level as the speciation of the second-generation nitrates changes. The resultant total extent of $\mathrm{NO}_{x}$ regeneration from the second-generation nitrates is between about 60 and $85 \%$ over the entire $\mathrm{NO}_{x}$ range (see Fig. 13). These results therefore suggest that between about 75 and $90 \%$ of $\mathrm{NO}_{x}$ is regenerated during the oxidation of the first- and second-generation nitrates, for the conditions of the present simulations.

Figure 12 also shows the simulated levels of PAN and total PANs, which are notably reduced in the MCM v3.3.1 simu- 

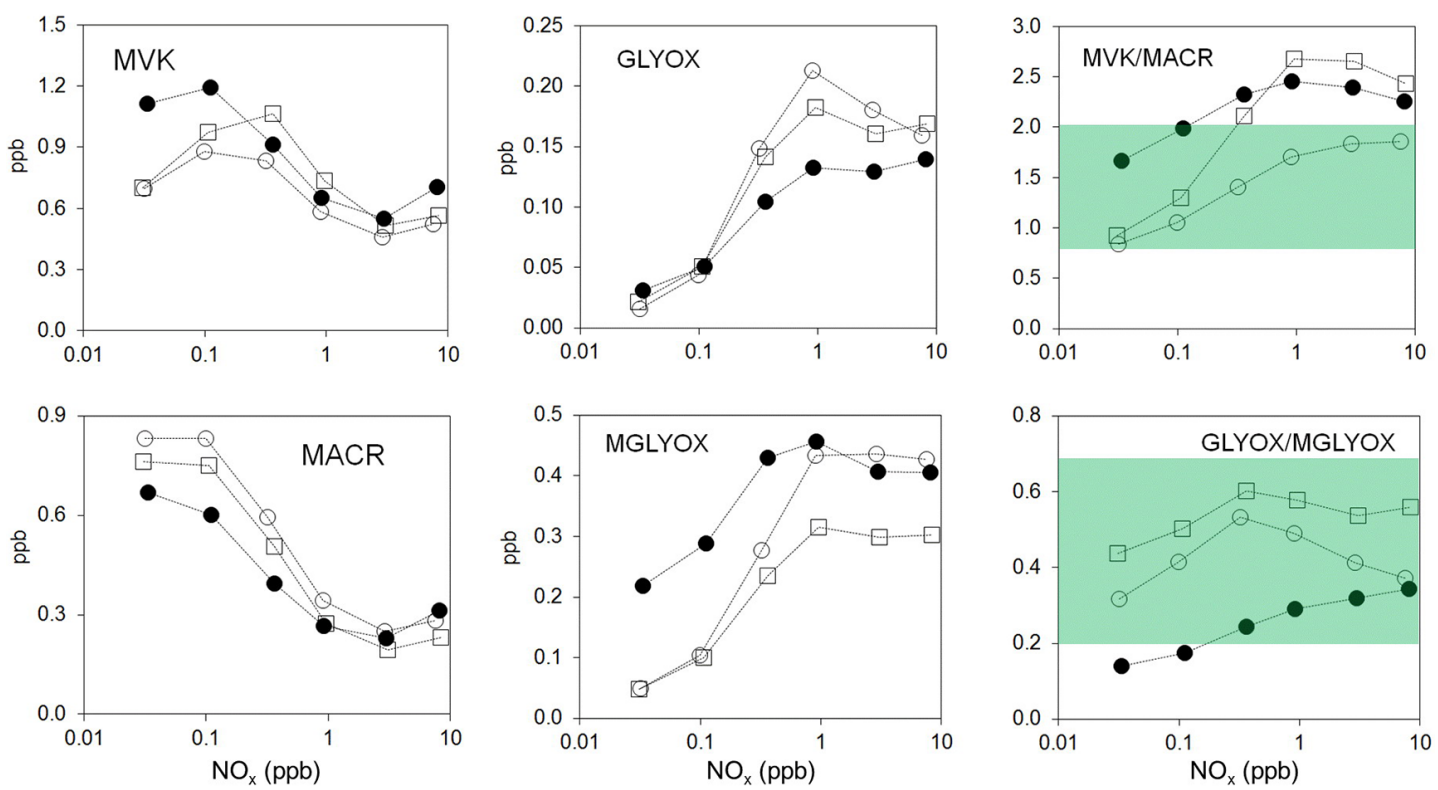

MCM v3.1 $\odot$ MCM v3.2

MCM v3.3.1

Figure 15. Comparison of the performances of MCM v3.1, MCM v3.2 and MCM v3.3.1, showing the $\mathrm{NO}_{x}$ dependence of the daylightaveraged mixing ratios of MVK, MACR, glyoxal (GLYOX) and methylglyoxal (MGLYOX); and the daylight-averaged ratios, MVK / MACR and GLYOX / MGLYOX. The shaded bands in the MVK / MACR and GLYOX / MGLYOX panels represent the typical ranges of reported observed values in isoprene-dominated environments (see text).

lation, mainly as a result of the update to the generic parameter applied to PAN decomposition (see Sect. 2.3). PAN consistently accounts for about $70 \%$ of the abundance of total PANs in all simulations and therefore makes the dominant contribution. The simulated levels of MPAN show a reduction in the MCM v3.2 simulation as a result of updates to the chemistry of MACR made at that time (e.g. including changes to the branching ratios of the initiation reaction with $\mathrm{OH}$ ), with further slight reductions resulting from those implemented in MCM v3.3.1. The PAN / MPAN ratio has typically been reported to lie in the approximate range of 4-10 in isoprene-dominated environments (e.g. Williams et al., 1997; Roberts et al., 2002, 2007). The ratios calculated using MCM v3.3.1 lie close to the upper bound of this range at the lower end of the considered $\mathrm{NO}_{x}$ range, although they reach values of up to about 20 towards the high end of the range. However, because PAN sources persist over several generations of isoprene oxidation, the PAN / MPAN ratio is expected to be sensitive to air mass age, with lower values at shorter extents of chemical processing that may not be fully captured by the idealised model used here, particularly at the high end of the $\mathrm{NO}_{x}$ range.

\subsubsection{Organic hydroperoxides and epoxides}

Figure 14 shows the simulated levels of organic hydroperoxides (i.e. species containing-OOH groups) and epoxides, and subsets of these totals. The results for the organic hydroperoxides show that the updates implemented in MCM v3.3.1 lead to a notable reduction in the simulated abundance of those formed from the traditional first-generation $\mathrm{OH}$-initiated chemistry (denoted "first-generation -OOH" in Fig. 14). To allow for direct comparison with the MCM v3.1 and MCM v3.2 results, this category specifically includes only those hydroperoxides formed from the reactions of $\mathrm{HO}_{2}$ with the first-generation peroxy radicals (denoted "ISOPO2" in Fig. 10). The reduced abundance results partly from the enhanced removal of the hydroperoxides by reaction with $\mathrm{OH}$, and partly because of the significant operation of the newly implemented peroxy radical isomerisation reactions in MCM v3.3.1, which compete directly with the $\mathrm{HO}_{2}$ reactions that form the hydroperoxides. However, it should be noted that the 1,6 $\mathrm{H}$ atom shift isomerisation reactions of CISOPAO2 and CISOPCO2 result in the formation of a suite of species that contain (one or more) hydroperoxide groups, with these also contributing to the first-generation hydroperoxide abundance via non-traditional mechanisms (see Fig. 3). These include the unsaturated hydroperoxyaldehydes (C5HPALD1 and C5HPALD2) and the dihydroperoxycarbonyls (DHPMEK and DHPMPAL), the abundances of which are also shown in Fig. 14. Inclusion of these species in the first-generation total leads to approximately a factor of 2 increase, as illustrated by the broken line in the "first- 
generation -OOH" panel. The significant operation of the $1,6 \mathrm{H}$ atom shift isomerisation chemistry also generally increases the abundance of higher-generation species containing hydroperoxide groups, as shown in the "total - $\mathrm{OOH}$ " panel of Fig. 14.

As described in Sect. 2.2.3, the epoxydiols (collectively denoted "IEPOX" in Fig. 14) are formed from the $\mathrm{OH}$-initiated chemistry of the traditional first-generation hydroxy-hydroperoxides, with this chemistry represented in MCM v3.2 and MCM v3.3.1. The updates to the chemistry in MCM v3.3.1 result in a general lowering of their abundance, because of the inhibition of the formation of the precursor hydroxy-hydroperoxides (as indicated above). The epoxydiols also make the dominant contribution to the total epoxide abundance in both the MCM v3.2 and MCM v3.3.1 simulations, but with additional notable contributions from the formation of HMML and MAE from the $\mathrm{OH}$-initiated chemistry of MPAN at the high end of the $\mathrm{NO}_{x}$ range in the MCM v3.3.1 results (see Sect. 2.2.1). The reaction of $\mathrm{OH}$ with HMML partially forms $\mathrm{HCOOH}$, as represented in MCM v3.3.1 (see Sects. 2.2.7 and S2.2). This source is simulated to make a notable contribution (about $30 \%$ ) to $\mathrm{HCOOH}$ formation towards the high end of the $\mathrm{NO}_{x}$ range for the conditions of these simulations, although its major source remains the reaction of water vapour with the stabilised Criegee intermediate $\mathrm{CH}_{2} \mathrm{OO}$, formed from isoprene ozonolysis (40$50 \%$ relative humidity). However, representation of reactive uptake of HMML on aerosol particles (e.g. Kjaergaard et al., 2012) would reduce the importance of its gas-phase degradation as a source of $\mathrm{HCOOH}$.

\subsubsection{Carbonyl product ratios}

Figure 15 shows the simulated levels of the well-established $\mathrm{C}_{4}$ unsaturated carbonyls (MVK and MACR), formed from the first-generation chemistry, and the $\alpha$-dicarbonyls (GLYOX and MGLYOX), which are formed over several generations of isoprene oxidation. In isoprene-dominated environments, observed ratios of these pairs of species have typically been reported to lie in the approximate ranges 0.8 2 for MVK/MACR (e.g. Spaulding et al., 2003; Kuhn et al., 2007; Karl et al., 2009) and 0.2-0.7 for glyoxal/methyl glyoxal (e.g. Lee et al., 1995, 1998; Spaulding et al., 2003). Figure 15 also shows the corresponding simulated daylightaveraged ratios in comparison to these observed ranges.

The updates to the first-generation chemistry in MCM v3.2 resulted in a reduction in the first-generation yield of MVK relative to that in MCM v3.1, leading to MVK/MACR ratios over the complete simulated $\mathrm{NO}_{x}$ range that are consistent with the reported range of observed values. As discussed in Sect. 2.1.4, the substantial changes to the firstgeneration chemistry in MCM v3.3.1 have tended to increase the first-generation yield of MVK relative to that of MACR at NO levels characteristic of the atmospheric range, leading to MVK/MACR ratios in the range 1.7-2.4, i.e. close to the upper bound of the reported range of observed values (Fig. 15).

The simulated levels of GLYOX and MGLYOX show some systematic differences resulting from the updates implemented in MCM v3.2 and MCM v3.3.1. These have resulted in a progressive suppression of the simulated GLYOX/MGLYOX ratios. Those simulated with MCM v3.3.1 (in the range 0.14-0.33) are close to the lower bound of the observed ratios over the complete $\mathrm{NO}_{x}$ range (Fig. 15).

\section{Summary and conclusions}

The chemistry of isoprene degradation in the Master Chemical Mechanism (MCM) has been systematically refined and updated to reflect recent advances in understanding, with these updates appearing in the latest version, MCM v3.3.1. The complete isoprene degradation mechanism in MCM v3.3.1 consists of 1926 reactions of 602 closed shell and free radical species, which treat the chemistry initiated by reaction with $\mathrm{OH}$ radicals, $\mathrm{NO}_{3}$ radicals and ozone $\left(\mathrm{O}_{3}\right)$. A detailed overview of the updates has been provided, with reference to the reported kinetic and mechanistic information on which they are based. The revisions mainly relate to the $\mathrm{OH}$-initiated chemistry, which generally dominates under atmospheric conditions, although these include updates to the chemistry of some products that are also generated from the $\mathrm{O}_{3}$ - and $\mathrm{NO}_{3}$-initiated oxidation. The revisions have impacts in a number of key areas, as illustrated by comparing the performance of the MCM v3.3.1 isoprene mechanism with those of earlier versions (MCM v3.1 and MCM v3.2) over a range of relevant conditions in a box model of the tropical forested boundary layer.

The updates have a collectively significant impact on $\mathrm{OH}$ radical regeneration at lower $\mathrm{NO}_{x}$ levels, with particularly important simulated contributions resulting from the chemistry initiated by the $1,6 \mathrm{H}$ atom shift isomerisation reactions of the $(Z) \delta$-hydroxy peroxy radicals, CISOPAO2 and CISOPCO2, and from the higher-generation $1,4 \mathrm{H}$ atom shift isomerisation reactions of the $\alpha$-formyl peroxy radicals (e.g. MACRO2, C57O2 and C58AO2).

The simulated recycling of $\mathrm{NO}_{x}$ from the degradation of oxidised organic nitrogen species has also been modified considerably by the updates. The degradation of organic nitrates formed from the first-generation $\mathrm{OH}$-initiated chemistry results in about $40 \%$ regeneration of $\mathrm{NO}_{x}$, owing to the dominance of their $\mathrm{OH}$-initiated removal, which leads significantly to products that retain the nitrate group. The degradation of the second-generation nitrates leads to much greater $\mathrm{NO}_{x}$ regeneration (60-85\%), owing to a major contribution from their rapid photolysis, with associated near-quantitative $\mathrm{NO}_{x}$ regeneration.

The updates also include the formation of a number of species that have been reported to play a role in SOAformation mechanisms, including epoxydiols (initially im- 
plemented in MCM v3.2), hydroxymethyl-methyl- $\alpha$-lactone (HMML) and methacrylic acid epoxide (MAE). Although the chemistry in MCM v3.3.1 is limited to gas-phase processes, the explicit formation of such species provides the basis for coupling with condensed-phase transfer mechanisms in simulations of detailed SOA composition, e.g. as described recently by Li et al. (2015).

The MCM v3.3.1 isoprene mechanism is believed to provide a valid description of the current detailed understanding of the atmospheric degradation of isoprene and a benchmark representation against which to develop and optimise reduced isoprene mechanisms. In addition, it also provides an ideal platform for testing the impacts of newly discovered mechanistic information relevant to isoprene degradation that is constantly emerging.

\section{Mechanism access and availability}

MCM v3.3.1 is available via the MCM website (http://mcm. leeds.ac.uk/MCM). A number of tools are provided which allow the mechanism to be downloaded or navigated online. The whole mechanism, or specified subsets, can be extracted in a variety of formats (including FACSIMILE, KPP, FORTRAN and XML), facilitating the construction of bespoke mechanisms which can be incorporated directly into atmospheric or chamber models. The complete mechanism treats the degradation of 143 emitted VOCs.

The isoprene subset mechanism described in the present paper can be downloaded by adding isoprene (C5H8) to the "Mark List" and using the "Extract" facility. The mechanism in FACSIMILE input format is also provided in the Supplement.

\section{The Supplement related to this article is available online at doi:10.5194/acp-15-11433-2015-supplement.}

Acknowledgements. This work was partially funded by the UK National Centre for Atmospheric Sciences (NCAS) and the UK Natural Environment Research Council (NERC) via grant NE/J008990/1. M. E. Jenkin also gratefully acknowledges funding as part of the Swedish Strategic Research Area ModElling the Regional and Global Earth system (MERGE) via Dave Simpson (MET Norway, Oslo; and Chalmers, Gothenburg), who is also thanked for helpful discussions. The authors are grateful to Jozef Peeters (University of Leuven), Jean-François Müller (Belgian Institute for Space Aeronomy), John Crounse (Caltech) and an anonymous referee, for review comments and suggestions that helped to improve both the mechanism and manuscript. David Waller (University of Leeds) and Stephen Pascoe (The NCAS British Atmospheric Data Centre) are also gratefully acknowledged for technical support with the MCM database and website.

Edited by: R. Sander

\section{References}

Alvarado, A., Atkinson, R., and Arey, J: Kinetics of the gas-phase reactions of $\mathrm{NO}_{3}$ radicals and $\mathrm{O}_{3}$ with 3-methylfuran and the $\mathrm{OH}$ radical yield from the $\mathrm{O}_{3}$ reaction, Int. J. Chem. Kinet., 28, 905-909, 1996.

Andreae, M. O. and Crutzen, P. J.: Atmospheric aerosols: biogeochemical sources and role in atmospheric chemistry, Science, 276, 1052-1058, 1997.

Archibald, A. T., Cooke, M. C., Utembe, S. R., Shallcross, D. E., Derwent, R. G., and Jenkin, M. E.: Impacts of mechanistic changes on $\mathrm{HO}_{x}$ formation and recycling in the oxidation of isoprene, Atmos. Chem. Phys., 10, 8097-8118, doi:10.5194/acp-108097-2010, 2010a.

Archibald, A. T., Jenkin, M. E., and Shallcross, D. E.: An isoprene mechanism intercomparison, Atmos. Environ., 44, 5356-5364, doi:10.1016/j.atmosenv.2009.09.016, 2010 b.

Arneth, A., Monson, R. K., Schurgers, G., Niinemets, Ü., and Palmer, P. I.: Why are estimates of global terrestrial isoprene emissions so similar (and why is this not so for monoterpenes)?, Atmos. Chem. Phys., 8, 4605-4620, doi:10.5194/acp-8-46052008, 2008.

Arneth, A., Harrison, S. P., Zaehle, S., Tsigaridis, K., Menon, S., Bartlein, P. J., Feichter, J., Korhola, A., Kulmala, M., O’Donnell, D., Schurgers, G., Sorvari, S., and Vesala, T.: Terrestrial biogeochemical feedbacks in the climate system, Nature Geosci., 3, 525-532, 2010.

Aschmann, S. M., Nishino, N., Arey, J., and Atkinson, R: Kinetics of the reactions of $\mathrm{OH}$ radicals with 2- and 3-methylfuran, 2,3and 2,5-dimethylfuran, and $E$ - and Z-3-hexene-2,5-dione, and products of $\mathrm{OH}+2,5$-dimethylfuran. Environ. Sci. Technol., 45, 1859-1865, 2011.

Aschmann, S. M., Nishino, N., Arey, J., and Atkinson, R: Products of the $\mathrm{OH}$ radical-initiated reactions of furan, 2- and 3methylfuran, and 2,3- and 2,5-dimethylfuran in the presence of NO, J. Phys. Chem. A, 118, 457-466, 2014.

Atkinson, R., Aschmann, S. M., Tuazon, E. C., Arey, J. and Zielinska, B.: Formation of 3-methylfuran from the gas-phase reaction of $\mathrm{OH}$ radicals with isoprene and the rate constant for its reaction with the OH radical, Int. J. Chem. Kinet., 21, 593-604, 1989.

Baker, J., Arey, J., and Atkinson, R.: Formation and reaction of hydroxycarbonyls from the reaction of $\mathrm{OH}$ radicals with 1,3butadiene and isoprene, Environ. Sci. Technol., 39, 4091-4099, 2005.

Bates, K. H., Crounse, J. D., St. Clair , J. M., Bennett, M. B., Nguyen, T. B., Seinfeld, J. H., Stoltz, B. M., and Wennberg, P. O.: Gas phase production and loss of isoprene epoxydiols, J. Phys. Chem. A, 118, 1237-1246, 2014.

Benkelberg, H.-J., Böge, O., Seuwen, R., and Warneck, P.: Product distributions from the $\mathrm{OH}$ radical-induced oxidation of but1-ene, methyl-substituted but-1-enes and isoprene in $\mathrm{NO}_{x}$-free air, Phys. Chem. Chem. Phys., 2, 4029-4039, 2000.

Berndt, T.: Formation of carbonyls and hydroperoxyenals (HPALDs) from the $\mathrm{OH}$ radical reaction of isoprene for low- $\mathrm{NO}_{x}$ conditions: influence of temperature and water vapour content, J. Atmos. Chem., 69, 253-272, 2000.

Brégonzio-Rozier, L., Siekmann, F., Giorio, C., Pangui, E., Morales, S. B., Temime-Roussel, B., Gratien, A., Michoud, V., Ravier, S., Cazaunau, M., Tapparo, A., Monod, A., and Doussin, J.-F.: Gaseous products and secondary organic aerosol forma- 
tion during long term oxidation of isoprene and methacrolein, Atmos. Chem. Phys., 15, 2953-2968, doi:10.5194/acp-15-29532015, 2015.

Butler, T. M., Taraborrelli, D., Brühl, C., Fischer, H., Harder, H., Martinez, M., Williams, J., Lawrence, M. G., and Lelieveld, J.: Improved simulation of isoprene oxidation chemistry with the ECHAM5/MESSy chemistry-climate model: lessons from the GABRIEL airborne field campaign, Atmos. Chem. Phys., 8, 4529-4546, doi:10.5194/acp-8-4529-2008, 2008.

Carter, W. P. L. and Atkinson, R.: Alkyl nitrate formation from the atmospheric photoxidation of alkanes; a revised estimation method, J. Atmos. Chem., 8, 165-173, 1989.

Chan, M. N., Surratt, J. D., Claeys, M., Edgerton, E. S., Tanner, R. L., Shaw, S. L., Zheng, M., Knipping, E. M., Eddingsaas, N. C., Wennberg, P. O., and Seinfeld, J. H.: Characterization and quantification of isoprene-derived epoxydiols in ambient aerosol in the southeastern United States, Environ. Sci. Technol., 44, 45904596, doi:10.1021/es100596b, 2010.

Claeys, M., Graham, B., Vas, G., Wang, W., Vermeylen, R., Pashynska, V., Cafmeyer, J., Guyon, P., Andreae, M. O., Artaxo, P., and Maenhaut, W.: Formation of secondary organic aerosols through photooxidation of isoprene, Science, 303, 1173-1176, 2004.

Crounse, J. D., Paulot, F., Kjaergaard, H. G., and Wennberg, P. O.: Peroxy radical isomerization in the oxidation of isoprene, Phys. Chem. Chem. Phys., 13, 13607-13613, 2011.

Crounse, J. D., Paulot, F., Kjaergaard, H. G., and Wennberg, P. O.: Additions and Corrections to: "Peroxy radical isomerization in the oxidation of isoprene, Phys. Chem. Chem. Phys., 2011, 13, 13607-13613 (doi:10.1039/C1CP21330J), Amendment published 6th September 2012, available at: http://www.rsc.org/ suppdata/cp/c1/c1cp21330j/addition.htm, 2012a.

Crounse, J. D., Knap, H. C., Ørnsø, K. B., Jørgensen, S., Paulot, F., Kjaergaard, H. G., and Wennberg, P. O.: Atmospheric fate of methacrolein. 1. Peroxy radical isomerization following addition of $\mathrm{OH}$ and $\mathrm{O}_{2}$, J. Phys. Chem. A, 116, 5756-5762, 2012b.

Crounse, J. D., Teng, A., and Wennberg, P. O.: Experimental constraints on the distribution and fate of peroxy radicals formed in reactions of isoprene $+\mathrm{OH}+\mathrm{O}_{2}$, presented at Atmospheric Chemical Mechanisms: Simple Models - Real World Complexities, University of California, Davis, USA, 10-12 December 2014.

Da Silva, G.: Hydroxyl radical regeneration in the photochemical oxidation of glyoxal: kinetics and mechanism of the $\mathrm{HC}(\mathrm{O}) \mathrm{CO}$ $+\mathrm{O}_{2}$ reaction, Phys. Chem. Chem. Phys., 12, 6698-6705, 2010.

Da Silva, G., Graham, C., and Wang, Z.-F.: Unimolecular $\beta$ hydroxyperoxy radical decomposition with $\mathrm{OH}$ recycling in the photochemical oxidation of isoprene, Environ. Sci. Technol., 44, 250-256, 2010.

Derwent, R. G., Collins, W. J., Jenkin, M. E, Johnson, C. E., and Stevenson, D. S.: The global distribution of secondary particulate matter in a 3-D Lagrangian chemistry transport model, J. Atmos. Chem., 44, 57-95, 2003.

Dibble, T. S.: Isomerization of $\mathrm{OH}-$ isoprene adducts and hydroxyalkoxy isoprene radicals, J. Phys. Chem. A, 106, 6643-6650, 2002.

Dibble, T. S.: Prompt chemistry of alkenoxy radical products of the double $\mathrm{H}$-atom transfer of alkoxy radicals from isoprene, J. Phys. Chem. A, 108, 2208-2215, 2004.
Dibble, T. S.: Cyclization of 1,4-hydroxycarbonyls is not a homogenous gas phase process, Chem. Phys. Lett., 447, 5-9, 2007.

Dillon, T. J. and Crowley, J. N.: Direct detection of $\mathrm{OH}$ formation in the reactions of $\mathrm{HO}_{2}$ with $\mathrm{CH}_{3} \mathrm{C}(\mathrm{O}) \mathrm{O}_{2}$ and other substituted peroxy radicals, Atmos. Chem. Phys., 8, 4877-4889, doi:10.5194/acp-8-4877-2008, 2008.

Eerdekens, G., Ganzeveld, L., Vilà-Guerau de Arellano, J., Klüpfel, T., Sinha, V., Yassaa, N., Williams, J., Harder, H., Kubistin, D., Martinez, M., and Lelieveld, J.: Flux estimates of isoprene, methanol and acetone from airborne PTR-MS measurements over the tropical rainforest during the GABRIEL 2005 campaign, Atmos. Chem. Phys., 9, 4207-4227, doi:10.5194/acp-9-42072009, 2009.

Francisco-Márquez, M., Alvarez-Idaboy, J. R., Galano, A., and Vivier-Bunge, A.: Theoretical study of the initial reaction between $\mathrm{OH}$ and isoprene in tropospheric conditions, Phys. Chem. Chem. Phys., 5, 1392-1399, 2003.

Froyd, K. D., Murphy, S. M., Murphy, D. M., de Gouw, J. A., Eddingsaas, N. C., and Wennberg, P. O.: Contribution of isoprenederived organosulfates to free tropospheric aerosol mass, P. Natl. Acad. Sci., 107, 21360-21365, doi:10.1073/pnas.1012561107, 2010.

Fuchs, H., Hofzumahaus, A., Rohrer, F., Bohn, B., Brauers, T., Dorn, H.-P., Häseler, R., Holland, F., Kaminski, M., Li, X., Lu, K., Nehr, S., Tillmann, R., Wegener, R., and Wahner, A.: Experimental evidence for efficient hydroxyl radical regeneration in isoprene oxidation, Nat. Geosci., 6, 1023-1026, doi:10.1038/NGEO1964, 2013.

Fuchs, H., Acir, I.-H., Bohn, B., Brauers, T., Dorn, H.-P., Häseler, R., Hofzumahaus, A., Holland, F., Kaminski, M., Li, X., Lu, K., Lutz, A., Nehr, S., Rohrer, F., Tillmann, R., Wegener, R., and Wahner, A.: $\mathrm{OH}$ regeneration from methacrolein oxidation investigated in the atmosphere simulation chamber SAPHIR, Atmos. Chem. Phys., 14, 7895-7908, doi:10.5194/acp-14-78952014, 2014.

Galloway, M. M., Huisman, A. J., Yee, L. D., Chan, A. W. H., Loza, C. L., Seinfeld, J. H., and Keutsch, F. N.: Yields of oxidized volatile organic compounds during the $\mathrm{OH}$ radical initiated oxidation of isoprene, methyl vinyl ketone, and methacrolein under high- $\mathrm{NO}_{\mathrm{x}}$ conditions, Atmos. Chem. Phys., 11, 10779-10790, doi:10.5194/acp-11-10779-2011, 2011.

Giacopelli, P., Ford, K., Espada, C., and Shepson, P. B.: Comparison of the measured and simulated isoprene nitrate distributions above a forest canopy, J. Geophys. Res., 110, D01304, doi:10.1029/2004JD005123, 2005.

Gómez Alvarez, E., Borrás, E., Viidanoja, J., and Hjorth, J.: Unsaturated dicarbonyl products from the $\mathrm{OH}$-initiated photo-oxidation of furan, 2-methylfuran and 3-methylfuran, Atmos. Environ., 43, 1603-1612, 2009.

Greenwald, E., North, S., Georgievskii, Y., and Klippenstein, S.: A two transition state model for radical-molecule reactions: applications to isomeric branching in the $\mathrm{OH}$-isoprene reaction, $\mathrm{J}$. Phys. Chem. A., 111, 5582-5592, 2007.

Groß, C. B. M., Dillon, T. J., Schuster, G., Lelieveld, J., and Crowley, J. N.: Direct kinetic study of $\mathrm{OH}$ and $\mathrm{O}_{3}$ formation in the reaction of $\mathrm{CH}_{3} \mathrm{C}(\mathrm{O}) \mathrm{O}_{2}$ with $\mathrm{HO}_{2}$, J. Phys. Chem. A, 118, 974 985, doi:10.1021/jp412380z, 2014.

Guenther, A., Hewitt, C. N., Erickson, D., Fall, R., Geron, C., Graedel, T., Harley, P., Klinger, L., Lerdau, M., McKay, W. A., 
Pierce, T., Scholes, B., Steinbrecher, R., Tallamraju, R., Taylor, J., and Zimmerman, P.: A global model of natural volatile organic compound emissions, J. Geophys. Res., 100, 8873-8892, 1995.

Haagen-Smit, A. J. and Fox, M. M.: Photochemical ozone formation with hydrocarbons and automobile exhaust, J. Air Pollut. Control Assoc., 4, 105-109, 1954.

Hallquist, M., Wenger, J. C., Baltensperger, U., Rudich, Y., Simpson, D., Claeys, M., Dommen, J., Donahue, N. M., George, C., Goldstein, A. H., Hamilton, J. F., Herrmann, H., Hoffmann, T., Iinuma, Y., Jang, M., Jenkin, M. E., Jimenez, J. L., Kiendler-Scharr, A., Maenhaut, W., McFiggans, G., Mentel, Th. F., Monod, A., Prévôt, A. S. H., Seinfeld, J. H., Surratt, J. D., Szmigielski, R., and Wildt, J.: The formation, properties and impact of secondary organic aerosol: current and emerging issues, Atmos. Chem. Phys., 9, 5155-5236, doi:10.5194/acp-9-51552009, 2009.

Hasson, A. S., Tyndall, G. S., and Orlando, J. J.: A product yield study of the reaction of $\mathrm{HO}_{2}$ Radicals with ethyl peroxy $\left(\mathrm{C}_{2} \mathrm{H}_{5} \mathrm{O}_{2}\right)$, acetyl peroxy $\left(\mathrm{CH}_{3} \mathrm{C}(\mathrm{O}) \mathrm{O}_{2}\right)$, and acetonyl peroxy $\left(\mathrm{CH}_{3} \mathrm{C}(\mathrm{O}) \mathrm{CH}_{2} \mathrm{O}_{2}\right)$ radicals, J. Phys. Chem. A, 108, 5979-5989, 2004.

Horowitz, L. W., Fiore, G. P., Milly, A. M., Cohen, R. C., Perring, A., Wooldridge, P. J., Hess, P. G., Emmons, L. K., and Lamarque, J.: Observational constraints on the chemistry of isoprene nitrates over the eastern United States, J. Geophys. Res., 112, D12S08, doi:10.1029/2006JD007747, 2007.

Jacobs, M. I., Darer, A. I., and Elrod, M. J.: Rate constants and products of the $\mathrm{OH}$ reaction with isoprene-derived epoxides, Environ. Sci. Technol., 47, 12868-12876, 2013.

Jenkin, M. E. and Clemitshaw, K. C.: Ozone and other secondary photochemical pollutants: chemical processes governing their formation in the planetary boundary layer, Atmos. Environ., 34, 2499-2527, 2000.

Jenkin, M. E., Murrells, T. P., Shalliker, S. J., and Hayman, G. D.: Kinetics and product study of the self-reactions of allyl and allyl peroxy radicals at 296 K, J. Chem. Soc. Faraday Trans., 89, 433446, 1993.

Jenkin, M. E., Saunders, S. M., and Pilling, M. J.: The tropospheric degradation of volatile organic compounds: a protocol for mechanism development, Atmos. Environ., 31, 81-104, 1997.

Jenkin, M. E., Hurley, M. D., and Wallington, T. J.: Investigation of the radical product channel of the $\mathrm{CH}_{3} \mathrm{C}(\mathrm{O}) \mathrm{O}_{2}+\mathrm{HO}_{2}$ reaction in the gas phase, Phys. Chem. Chem. Phys., 9, 3149-3162, 2007.

Jenkin, M. E., Young, J. C., and Rickard, A. R.: The MCM v3.3 degradation scheme for isoprene, Atmos. Chem. Phys. Discuss., 15, 9709-9766, doi:10.5194/acpd-15-9709-2015, 2015.

Karl, M., Dorn, H.-P., Holland, F., Koppmann, R., Poppe, D., Rupp, L., Schaub, A., and Wahner, A.: Product study of the reaction of $\mathrm{OH}$ radicals with isoprene in the atmosphere simulation chamber SAPHIR, J. Atmos. Chem., 55, 167-187, 2006.

Karl, T., Guenther, A., Turnipseed, A., Tyndall, G., Artaxo, P., and Martin, S.: Rapid formation of isoprene photo-oxidation products observed in Amazonia, Atmos. Chem. Phys., 9, 7753-7767, doi:10.5194/acp-9-7753-2009, 2009.

Kjaergaard, H. G., Knap, H. C., Ornso, K. B., Jorgensen, S., Crounse, J. D., Paulot, F., and Wennberg, P. O.: Atmospheric fate of methacrolein. 2. Formation of lactone and implications for organic aerosol production, J. Phys. Chem. A, 116, 5763-5768, doi:10.1021/jp210853h, 2012.
Kuhn, U., Andreae, M. O., Ammann, C., Araújo, A. C., Brancaleoni, E., Ciccioli, P., Dindorf, T., Frattoni, M., Gatti, L. V., Ganzeveld, L., Kruijt, B., Lelieveld, J., Lloyd, J., Meixner, F. X., Nobre, A. D., Pöschl, U., Spirig, C., Stefani, P., Thielmann, A., Valentini, R., and Kesselmeier, J.: Isoprene and monoterpene fluxes from Central Amazonian rainforest inferred from towerbased and airborne measurements, and implications on the atmospheric chemistry and the local carbon budget, Atmos. Chem. Phys., 7, 2855-2879, doi:10.5194/acp-7-2855-2007, 2007.

Langner, J., Engardt, M., Baklanov, A., Christensen, J. H., Gauss, M., Geels, C., Hedegaard, G. B., Nuterman, R., Simpson, D., Soares, J., Sofiev, M., Wind, P., and Zakey, A.: A multi-model study of impacts of climate change on surface ozone in Europe, Atmos. Chem. Phys., 12, 10423-10440, doi:10.5194/acp12-10423-2012, 2012.

Lee, L., Teng, A. P., Wennberg, P. O., Crounse, J. D., and Cohen, R. C.: On rates and mechanisms of $\mathrm{OH}$ and $\mathrm{O}_{3}$ reactions with isoprene-derived hydroxy nitrates, J. Phys. Chem. A, 118, 1622 1637, 2014.

Lee, Y. N., Zhou, X., and Hallock, K.: Atmospheric carbonyl compounds at a rural southeastern U.S. site, J. Geophys. Res., 100, 25933-25944, 1995.

Lee, Y. N., Zhou, X., Kleinman, L. I., Nunnermacker, L. J., Springston, S. R., Daum, P. H., Newman, L., Keigley, W. G., Holdren, M. W., Spicer, C. W., Parrish, D. D., Holloway, J., Williams, J., Roberts, J. M., Ryerson, T. B., Fehsenfeld, F. C., Young, V., and Fu, B.: Atmospheric chemistry and distribution of formaldehyde and several multi-oxygenated carbonyl compounds during the 1995 Nashville/Middle Tennessee ozone study, J. Geophys. Res., 103, 22449-22462, 1998.

Lee, W., Baasandorj, M., Stevens, P. S., and Hites, R. A.: Monitoring $\mathrm{OH}$-initiated oxidation kinetics of isoprene and its products using online mass spectrometry, Environ. Sci. Technol., 39, 1030-1036, 2005.

Lei, W., Zhang, R., McGivern, W. S., Derecskei-Kovacs, A. and North, S. W.: Theoretical study of isomeric branching in the isoprene- $\mathrm{OH}$ reaction: implications to final product yields in isoprene oxidation, Chem. Phys. Lett., 326, 109-114, 2000.

Lelieveld, J., Butler, T. M., Crowley, J. N., Dillon, T. J., Fischer, H., Ganzeveld, L., Harder, H., Lawrence, M. G., Martinez, M., Taraborrelli, D., and Williams, J.: Atmospheric oxidation capacity sustained by a tropical forest, Nature, 452, 737-740, 2008.

Li, J., Cleveland, M., Ziemba, L. D., Griffin, R. J., Barsanti, K. C., Pankow, J. F., and Ying, Q.: Modeling regional secondary organic aerosol using the Master Chemical Mechanism, Atmos. Environ., 102, 52-61, 2015.

Lightfoot, P. D., Cox, R. A., Crowley, J. N., Destriau, M., Hayman, G. D., Jenkin, M. E., Moortgat, G. K., and Zabel, F.: Organic peroxy radicals: kinetics, spectroscopy and tropospheric chemistry, Atmos. Environ., 26A, 1805-1964, 1992.

Lin, Y.-H., Zhang, Z., Docherty, K. S., Zhang, H., Budisulistiorini, S. H., Rubitschun, C. L., Shaw, S. L., Knipping, E. M., Edgerton, E. S., Kleindienst, T. E., Gold, A., and Surratt, J. D.: Isoprene epoxydiols as precursors to secondary organic aerosol formation: acid-catalyzed reactive uptake studies with authentic compounds, Environ. Sci. Technol., 46, 250-258, doi:10.1021/es202554c, 2011.

Lin, Y.-H., Zhanga, H., Pye, H. O., Zhanga, Z., Martha, W. J., Parka, S., Arashiroa, M., Cuia, T., Budisulistiorinia, S. H., Sex- 
tona, K. G., Vizuetea, W., Xieb, Y., Lueckenb, D. J., Pileticb, I. R., Edneyb, E. O., Bartolottic, L. J., Gold, A., and Surratt, S. D.: Epoxide as a precursor to secondary organic aerosol formation from isoprene photooxidation in the presence of nitrogen oxides, Environ. Sci. Technol., 110, 6718-6723, doi:10.1073/pnas.1221150110, 2013.

Liu, Y. J., Herdlinger-Blatt, I., McKinney, K. A., and Martin, S. T.: Production of methyl vinyl ketone and methacrolein via the hydroperoxyl pathway of isoprene oxidation, Atmos. Chem. Phys., 13, 5715-5730, doi:10.5194/acp-13-5715-2013, 2013.

Lockhart, J., Blitz, M., Heard, D., Seakins, P., and Shannon, R.: Kinetic study of the $\mathrm{OH}+$ glyoxal reaction: experimental evidence and quantification of direct $\mathrm{OH}$ recycling, J. Phys. Chem. A, 117, 11027-11037, 2013.

Lockwood, A. L., Shepson, P. B., Fiddler, M. N., and Alaghmand, M.: Isoprene nitrates: preparation, separation, identification, yields, and atmospheric chemistry, Atmos. Chem. Phys., 10, 6169-6178, doi:10.5194/acp-10-6169-2010, 2010.

Martinez, M., Harder, H., Kovacs, T. A., Simpas, J. B., Bassis, J., Lesher, R., Brune, W. H., Frost, G. J., Williams, E. J., and Stroud, C. A.: $\mathrm{OH}$ and $\mathrm{HO}_{2}$ concentrations, sources, and loss rates during the Southern Oxidants Study in Nashville, Tennessee, summer 1999, J. Geophys. Res., 108, 4617, doi:10.1029/2003JD003551, 2003.

McGivern, W. S., Suh, I., Clinkenbeard, A. D., Zhang, R., and North, S. W.: Experimental and computational study of the OHisoprene reaction: isomeric branching and low-pressure behavior, J. Phys. Chem. A, 104, 6609-6616, 2000.

Müller, J.-F.: Interactive comment on "The MCM v3.3 degradation scheme for isoprene" by M. E. Jenkin et al., Atmos. Chem. Phys. Discuss., 15, C2570-C2573, 2015.

Müller, J.-F., Peeters, J., and Stavrakou, T.: Fast photolysis of carbonyl nitrates from isoprene, Atmos. Chem. Phys., 14, 24972508, doi:10.5194/acp-14-2497-2014, 2014.

Navarro, M. A., Dusanter, S., and Stevens, P. S.: Temperature dependence of the yields of methacrolein and methyl vinyl ketone from the $\mathrm{OH}$-initiated oxidation of isoprene under $\mathrm{NO}_{x}$-free conditions, Atmos. Environ., 79, 59-66, 2013.

Nguyen, V. S. and Peeters, J.: Fast $(E)-(Z)$ isomerization mechanisms of substituted allyloxy radicals in isoprene oxidation, J. Phys. Chem. A, 119, 7270-7276, doi:10.1021/jp512057t, 2015.

Orlando, J. and Tyndall, G. S: The atmospheric chemistry of the HC(O)CO radical, Int. J. Chem. Kinet., 33, 149-156, 2001.

Park, J., Jongsma, C. G., Zhang, R. Y., and North, S. W.: Cyclization reactions in isoprene derived $\beta$-hydroxy radicals: implications for the atmospheric oxidation mechanism, Phys. Chem. Chem. Phys., 5, 3638-3642, 2003.

Paulot, F., Crounse, J. D., Kjaergaard, H. G., Kürten, A., St. Clair, J. M., Seinfeld, J. H., and Wennberg, P. O.: Unexpected epoxide formation in the gas-phase photooxidation of isoprene, Science, 325, 730-733, 2009a.

Paulot, F., Crounse, J. D., Kjaergaard, H. G., Kroll, J. H., Seinfeld, J. H., and Wennberg, P. O.: Isoprene photooxidation: new insights into the production of acids and organic nitrates, Atmos. Chem. Phys., 9, 1479-1501, doi:10.5194/acp-9-1479-2009, 2009b.

Paulson, S. E., Flagan, R. C., and Seinfeld, J. H.: Atmospheric photo-oxidation of isoprene: part I. The hydroxyl radical and ground state atomic oxygen reactions, Int. J. Chem. Kinet., 24, 79-101, 1992.
Peeters, J.: Interactive comment on "The MCM v3.3 degradation scheme for isoprene" by M. E. Jenkin et al., Atmos. Chem. Phys. Discuss., 15, C2486, 2015.

Peeters, J. and Müller, J.-F.: $\mathrm{HO}_{x}$ radical regeneration in isoprene oxidation via peroxy radical isomerisations, II: Experimental evidence and global impact, Phys. Chem. Chem. Phys., 10, 1422714235, 2010.

Peeters, J. and Nguyen, T. L: Unusually fast 1,6-H shifts of enolic hydrogens in peroxy radicals: formation of the first-generation $\mathrm{C}_{2}$ and $\mathrm{C}_{3}$ carbonyls in the oxidation of isoprene, J. Phys. Chem. A, 116, 6134-6141, 2012.

Peeters, J., Nguyen, T. L., and Vereecken, L.: $\mathrm{HO}_{x}$ radical regeneration in the oxidation of isoprene, Phys. Chem. Chem. Phys., 28, 5935-5939, 2009.

Peeters, J., Müller, J.-F., Stavrakou, T., and Nguyen, V. S.: Hydroxyl radical recycling in isoprene oxidation driven by hydrogen bonding and hydrogen tunneling: the upgraded LIM1 mechanism, J. Phys. Chem. A, 118, 8625-8643, 2014.

Peñuelas, J. and Staudt, M.: BVOCs and global change, Trends in Plant Science, 15, 133-144, doi:10.1016/j.tplants.2009.12.005, 2010.

Perring, A. E., Bertram, T. H., Wooldridge, P. J., Fried, A., Heikes, B. G., Dibb, J., Crounse, J. D., Wennberg, P. O., Blake, N. J., Blake, D. R., Brune, W. H., Singh, H. B., and Cohen, R. C.: Airborne observations of total $\mathrm{RONO}_{2}$ : new constraints on the yield and lifetime of isoprene nitrates, Atmos. Chem. Phys., 9, 14511463, doi:10.5194/acp-9-1451-2009, 2009.

Pinho, P. G., Pio, C. A., and Jenkin, M. E.: Evaluation of isoprene degradation in the detailed tropospheric chemical mechanism, MCM v3, using environmental chamber data, Atmos. Environ., 39, 1303-1322, 2005.

Ren, X., Olson, J. R., Crawford, J. H., Brune, W. H., Mao, J., Long, R. B., Chen, Z., Chen, G., Avery, M. A., and Sachse, G. W.: $\mathrm{HO}_{x}$ chemistry during INTEX-A 2004: Observation, model calculation, and comparison with previous studies, J. Geophys. Res., 113, D05310, doi:10.1029/2007JD009166, 2008.

Roberts, J. M., Flocke, F., Stroud, C. A., Hereid, D., Williams, E. J., Fehsenfeld, F. C., Brune, W., Martinez, M., and Harder, H.: Ground-based measurements of PANs during the 1999 Southern Oxidants Study Nashville intensive, J. Geophys. Res., 107, 4554, doi:10.1029/2001JD000947, 2002.

Roberts, J. M., Marchewka, M., Bertman, S. B., Sommariva, R., Warneke, C., de Gouw, J., Kuster, W., Goldan, P., Williams, E., Lerner, B. M., Murphy, P., and Fehsenfeld, F. C.: Measurements of PANs during the New England Air Quality Study 2002, J. Geophys. Res., 112, D20306, doi:10.1029/2007JD008667, 2007.

Ruppert, L. and Becker, K.-H.: A product study of the $\mathrm{OH}$ radicalinitiated oxidation of isoprene: formation of $\mathrm{C}_{5}$-unsaturated diols, Atmos. Environ., 34, 1529-1542, 2000.

Saunders, S. M., Jenkin, M. E., Derwent, R. G., and Pilling, M. J.: Protocol for the development of the Master Chemical Mechanism, MCM v3 (Part A): tropospheric degradation of nonaromatic volatile organic compounds, Atmos. Chem. Phys., 3, 161-180, doi:10.5194/acp-3-161-2003, 2003.

Simpson, D., Arneth, A., Mills, G., Solberg, S., and Uddling, J.: Ozone - the persistent menace; interactions with the $\mathrm{N}$ cycle and climate change, Curr. Opin. Env. Sust., 9-10, 9-19, 2014.

Spaulding, R. S., Schade, G. W., Goldstein, A. H., and Charles, M. J.: Characterization of secondary atmospheric photooxidation 
products: Evidence for biogenic and anthropogenic sources, J. Geophys. Res., 108, 4247, doi:10.1029/2002JD002478, 2003.

Stavrakou, T., Peeters, J., and Müller, J.-F.: Improved global modelling of $\mathrm{HO}_{\mathrm{x}}$ recycling in isoprene oxidation: evaluation against the GABRIEL and INTEX-A aircraft campaign measurements, Atmos. Chem. Phys., 10, 9863-9878, doi:10.5194/acp-10-98632010, 2010.

Stone, D., Evans, M. J., Edwards, P. M., Commane, R., Ingham, T., Rickard, A. R., Brookes, D. M., Hopkins, J., Leigh, R. J., Lewis, A. C., Monks, P. S., Oram, D., Reeves, C. E., Stewart, D., and Heard, D. E.: Isoprene oxidation mechanisms: measurements and modelling of $\mathrm{OH}$ and $\mathrm{HO}_{2}$ over a South-East Asian tropical rainforest during the OP3 field campaign, Atmos. Chem. Phys., 11, 6749-6771, doi:10.5194/acp-11-6749-2011, 2011.

Suarez-Bertoa, R., Picquet-Varrault, B., Tamas, W., Pangui, E., and Doussin, J.-F.: Atmospheric fate of a series of carbonyl nitrates: photolysis frequencies and $\mathrm{OH}$-oxidation rate constants, Environ. Sci. Technol., 46, 12502-12509, 2012.

Tan, D., Faloona, I., Simpas, J. B., Brune, W., Shepson, P. B., Couch, T. L., Sumner, A. L., Carroll, M. A., Thornberry, T., and Apel, E.: $\mathrm{HO}_{x}$ budgets in a deciduous forest: Results from the PROPHET summer 1998 campaign, J. Geophys. Res., 106, D20, doi:10.1029/2001JD900016, 2001.

Taraborrelli, D., Lawrence, M. G., Crowley, J. N., Dillon, T. J., Gromov, S., Groß, C. B. M., Vereecken, L., and Lelieveld, J.: Hydroxyl radical buffered by isoprene oxidation over tropical forests, Nat. Geosci., 5, 190-193, 2012.

Teng, A. P., Crounse, J. D., Lee, L., St. Clair, J. M., Cohen, R. C., and Wennberg, P. O.: Hydroxy nitrate production in the $\mathrm{OH}-$ initiated oxidation of alkenes, Atmos. Chem. Phys., 15, 42974316, doi:10.5194/acp-15-4297-2015, 2015.

Thornton, J. A., Wooldridge, P. J., Cohen, R. C., Martinez, M., Harder, H., Brune, W. H., Williams, E. J., Roberts, J. M., Fehsenfeld, F. C., Hall, S. R., Shetter, R. E., Wert, B. P., and Fried, A.: Ozone production rates as a function of $\mathrm{NO}_{x}$ abundances and $\mathrm{HO}_{x}$ production rates in the Nashville urban plumes, J. Geophys. Res., 107, 4146, doi:10.1029/2001JD000932, 2002.

Vereecken, L. and Peeters, J.: Decomposition of substituted alkoxy radicals - part I: a generalized structure-activity relationship for reaction barrier heights, Phys. Chem. Chem. Phys., 11, 90629074, 2009.
Volkamer, R., Barnes, I., Platt, U., Molina, L. T., and Molina, M. J.: Remote sensing of glyoxal by differential optical absorption spectroscopy (DOAS): Advancements in simulation chamber and field experiments, in: Environmental Simulation Chambers: Application to Atmospheric Chemical Processes, edited by: Barnes, I. and Rudinski, J., Springer, Dordrecht, Netherlands, 62, 2006.

Warneke, C., de Gouw, J. A., Del Negro, L., Brioude, J., McKeen, S., Stark, H., Kuster, W. C., Goldan, P. D., Trainer, M., Fehsenfeld, F. C., Wiedinmyer, C., Guenther, A. B., Hansel, A., Wisthaler, A., Atlas, E., Holloway, J. S., Ryerson, T. B., Peischl, J., Huey, L. G., and Hanks, A. T. C.: Biogenic emission measurement and inventories determination of biogenic emissions in the eastern United States and Texas and comparison with biogenic emission inventories, J. Geophys. Res., 115, D00F18, doi:10.1029/2009JD012445, 2010.

Went, F. W.: Blue hazes in the atmosphere, Nature, 187, 641-645, 1960.

Williams, J., Roberts, J. M., Fehsenfeld, F. C., Bertman, S. B., Buhr, M. P., Goldan, P. D., G. Hubler, G., Kuster, W. C., Ryerson, T. B., Trainer, M., and Young, V.: Regional ozone from biogenic hydrocarbons deduced from airborne measurements of PAN, PPN and MPAN, Geophys. Res. Lett., 24, 1099-1102, 1997.

Wolfe, G. M., Crounse, J. D., Parrish, J. D., St. Clair, J. M., Beaver, M. R., Paulot, F., Yoon, T. P., Wennberg, P. O., and Keutsch, F. N.: Photolysis, $\mathrm{OH}$ reactivity and ozone reactivity of a proxy for isoprene-derived hydroperoxyenals (HPALDs), Phys. Chem. Chem. Phys., 14, 7276-7286, 2012.

Zhang, W., Du, B., Mu, L., and Feng, C.: Mechanism for the gasphase reaction between $\mathrm{OH}$ and 3-methylfuran: a theoretical study, Int. J. Quantum. Chem., 108, 1232-1238, 2008.

Zhao, J., Zhang, R. Y., and North, S. W.: Oxidation mechanism of delta-hydroxyisoprene alkoxy radicals: hydrogen abstraction versus 1,5 H-shift, Chem. Phys. Lett., 369, 204-213, 2003.

Zhao, J., Zhang, R. Y., Fortner, E. C., and North, S. W.: Quantification of hydroxycarbonyls from $\mathrm{OH}$-isoprene reactions, J. Am. Chem. Soc., 126, 2686-2687, 2004. 